\title{
LOS PALACIOS DE LOS DUQUES DE MEDINACELI EN EL ENTORNO DEL PASEO DEL PRADO DURANTE EL SIGLO XVIII*
}

\author{
María Teresa Cruz YÁbar ${ }^{1}$ \\ Universidad Complutense de Madrid
}

\begin{abstract}
Los duques de Medinaceli tuvieron dos posesiones en las cercanías del paseo del Prado que alcanzaron fama, en especial el palacio que ocupó todo el frente de la última manzana de la carrera de San Jerónimo, considerado la principal casa del duque en Madrid. La otra se conoció en la época como palacio del marqués de Cogolludo, situada entre la calle de Atocha y la de la Magdalena. En este trabajo abordamos el examen de las noticias del siglo XVIII que se conocen sobre ellas, las cuales no han sido analizadas con rigor. Brevemente nos referiremos a otras dos propiedades cercanas, que a veces han sido confundidas con las anteriores.
\end{abstract}

Palabras clave: Francisco Sabatini; Manuel López Corona; Manuel Bradi; Juan Antonio de Castro; Francisco Sánchez; Arquitectura; Madrid.

\section{THE DUKES OF MEDINACELI'S PALACES IN THE SURROUNDING OF THE PASEO DEL PRADO IN THE $18^{\text {TH }}$ CENTURY}

The Dukes of Medinaceli owned two renowned properties near the Paseo del Prado. Most prominently, the palace that occupied the entire front of the last block of the Carrera de San Jeronimo became the duke's main residence in Madrid. The other, known as the Palace of the Marquis of Cogolludo, was located between Atocha and Magdalena streets. This article explores eighteenth-century documentation pertaining to both homes, which has not been rigorously analysed to date. Two other nearby properties, which at times have been mistaken with the main residences, also are briefly considered.

Key words: Francisco Sabatini; Manuel López Corona; Manuel Bradi; Juan Antonio de Castro; Francisco Sánchez; Architecture; Madrid.

Cómo citar este artículo / Citation: Cruz Yábar, María Teresa (2021) "Los palacios de los Duques de Medinaceli en el entorno del paseo del Prado durante el siglo XVIII". En: Archivo Español de Arte, vol. 94, núm. 376, Madrid, pp. 387-406. https://doi.org/10.3989/aearte.2021.22

* Este trabajo es fruto de la investigación realizada en el marco del proyecto I+D del Plan Nacional PGC2018094432-B-I00: El artista en el ámbito académico madrileño (1759-1833): su formación, producción artística y clientela (MCI/AEI/FEDER, UE) del Grupo de Investigación UCM 970866 "Patrimonio cultural y sociología artística, artífices, obras y clientes en los territorios de la Monarquía hispánica (1516-1833)”. Agradezco la rapidez en la gestión y envío de las fotografías al personal de la Biblioteca Nacional de España y muy especialmente al de los Archivos de la Villa de Madrid y de la Fundación Casa Ducal de Medinaceli, instituciones a quienes, además, expreso mi mayor agradecimiento por su generosidad en la cesión de las imágenes para su reproducción en este artículo.

1 mtcruz@ucm.es / ORCID iD: https://orcid.org/0000-0001-9423-0672 
La trayectoria vital de los titulares del ducado de Medinaceli durante el siglo XVIII influyó en la edificación, ampliación o reforma de sus palacios madrileños. Reseñamos a continuación algunas circunstancias que pudieron tener trascendencia en el acontecer de estas posesiones en el periodo estudiado. ${ }^{2}$

Luis Francisco de la Cerda y Aragón (1660-1711), IX duque desde 1691, fue designado embajador en Roma en 1687, siendo aún marqués de Cogolludo. ${ }^{3}$ En 1696 recibió nombramiento de virrey de Nápoles, y, tras una conjura, fue relevado en 1702. Ya en Madrid, sus relaciones con el nuevo monarca Borbón no fueron pacíficas, a pesar de lo cual fue designado ayo del príncipe en 1709 y encargado de la política exterior en 1710. Pero Felipe V, por motivos no bien conocidos pero relacionados con su desconfianza hacia el duque, le hizo arrestar el 15 de abril de 1710. Enviado preso a la fortaleza de Pamplona, murió allí al año siguiente.

Por ausencia de sucesores directos, heredó todos sus títulos su sobrino Nicolás Fernández de Córdoba y de la Cerda, hijo de su hermana Feliche. Nacido en 1682, estaba casado con la milanesa Jerónima Espínola y de la Cerda (1687-1757), su prima, hija del marqués de los Balbases, con la que tuvo ocho hijos. A la llegada de la nueva dinastía fue designado gentilhombre de la cámara y Felipe V selló la paz con los Medinaceli cuando pasó a vivir unos meses en su casa del Prado tras la muerte de la reina en 1714. El rey se lo agradeció haciéndole su embajador extraordinario encargado de recibir a la nueva reina Isabel Farnesio. Don Nicolás acompañó a los reyes durante el lustro real por tierras andaluzas (1729-1733), fue nombrado caballerizo mayor de la reina y en 1737 su mayordomo mayor. ${ }^{4}$ Pretendió renovar su palacio del Puerto de Santa María ${ }^{5}$-intento frustrado cuando el rey le privó del señorío de esa villa en 1729- y también la Casa de Pilatos de Sevilla en 1731 durante la estancia de la Corte. ${ }^{6} \mathrm{El} \mathrm{X}$ duque falleció en 1739 y su esposa le sobrevivió 18 años.

Su hijo Luis Antonio Fernández de Córdoba y Spínola, disfrutó del título de XI duque de Medinaceli durante casi treinta años, y residió la mayor parte del tiempo en Madrid. Había nacido en 1704; militar, llegó a ser teniente general de los Reales Ejércitos. Casó en 1722 con la marquesa de Aytona, y de nuevo en 1763 con la jovencísima María Francisca Pignatelli de Aragón y Gonzaga, hija del conde de Fuentes, que moriría un año después que su esposo. El duque gozó de muy buena relación con Fernando VI y Carlos III, y fue caballerizo mayor desde 1749 hasta su muerte en 1768. En 1765, la casa y huerta del duque sirvieron de escenario a una gran fiesta dada en honor del príncipe Carlos y su esposa María Luisa con ocasión de su matrimonio. ${ }^{7}$ Consideramos que fue quien, al final de su vida, adoptó la decisión de aumentar y modernizar el palacio del Prado.

Heredó el título su hijo Pedro de Alcántara Fernández de Córdoba de la Cerda y Moncada, nacido en 1730, casado primero con M. ${ }^{a}$ Francisca Gonzaga, hija del duque de Solferino, y en segundas nupcias con María Petronila de Alcántara Pimentel y Cernesio, marquesa de Malpica, Mancera y Povar (1746-1802). Llegó a ser mayordomo mayor del rey y reunió en su persona un sinnúmero de grandes títulos nobiliarios y enorme fortuna. Se le conoce importantes patrocinios, como la gran medalla de mármol y la urna del Santo de su nombre en su capilla de Arenas de San Pedro ${ }^{8}$ y, cabe recordar, los memorables ornatos efímeros de los palacios del Prado y de Atocha en septiembre de 1789 con motivo de la exaltación al trono de Carlos IV, en que gastó ingentes cantidades y que llegó a ver por muy poco, ya que murió el 24 de noviembre siguiente. En 1765, siendo aún marqués de Cogolludo, intentó la primera reforma del palacio de la calle de Atocha.

\footnotetext{
${ }^{2}$ Dado que la bibliografía sobre los duques es amplísima, para la fuente de los datos recogidos en este apartado de nuestro trabajo nos remitimos, si no está expresamente citado en nota, a las correspondientes voces del Diccionario de la Real Academia de la Historia que hemos consultado.

3 Título que habitualmente ostentaba el primogénito del duque de Medinaceli.

${ }^{4}$ Martínez Millán, 2009: 636-639.

5 Romero Medina, 2004.

${ }^{6}$ Morales y Quiles García, 2010: 211.

${ }^{7}$ Festejos por los casamientos del Príncipe nuestro señor, 1765-1766. Archivo de la Villa de Madrid (AVM), Secretaría, 2-76-5 y Carta de Manuel Martínez Pingarrón a Gregorio Mayans y Siscar sobre el gasto de 250.000 ducados de Medinaceli en esta ocasión, 26 de noviembre de 1765 en: Mayans y Siscar.

${ }^{8}$ Cruz Yábar, 2017:187.
} 
El XIII duque, último del periodo, Luis María Fernández de Córdoba y Gonzaga, nació en 1749, ejerció como militar siendo promovido a teniente general en 1795 y fue mayordomo de la reina María Luisa. Las largas estancias del monarca en El Escorial y Aranjuez propiciaron que el duque se hiciera construir allí sendas casas de jornada, la primera cuando aún era marqués de Cogolludo. Hizo aumentar la altura de su palacio del Prado y emprendió en 1800 el gran proyecto del palacio de Atocha que, desgraciadamente, no se llevó a efecto, quizá porque el duque falleció en 1806.

\section{El palacio de la carrera de San Jerónimo}

\section{La Huerta del duque de Lerma}

La situación de este palacio, edificado sobre una parte de lo que fue a principios del siglo XVII la huerta del duque de Lerma, ha hecho que se le haya considerado su heredero.

La forma en que el valido de Felipe III fue adquiriendo esos terrenos para agrandar la huerta que él mismo poseía allí antes de que la Corte marchara a Valladolid ha sido un asunto estudiado en profundidad por Muñoz de la Nava, ${ }^{9}$ que ha reunido interesantes imágenes del palacio de Lerma en fechas tempranas, incluidos los miradores que debió de trazar Francisco de Mora hacia 1603 y que estaban ya construidos cuando la Corte volvió a Madrid en 1606. ${ }^{10}$ Los detalles de la ornamentación de los jardines y construcción del cuarto principal por el maestro Pedro de Herrera con trazas de Juan Gómez de Mora a partir de 1614 están expuestos con detalle por Lopezosa Aparicio. ${ }^{11}$ En todas las representaciones, incluidos los planos de Witt (Antonio Mancelli, 1622) y Teixeira (1656), lo edificado por la calle del Prado - recientemente abierta entonces - ocupaba unos 50 o 60 pies, avanzaba apenas un tercio de la línea de la manzana a la carrera de San Jerónimo y el resto hasta el paseo del Prado eran tapias, con una entrada al jardín.

Poco tienen que ver, aparentemente, el edificio levantado por Juan Gómez de Mora y el palacio de Medinaceli que conocemos por fotografías del siglo XIX, una construcción realizada a mediados del siglo XVIII en un claro estilo clasicista romano. Tampoco su extensión, que ahora se prolongaba en una larguísima crujía que ocupaba todo el frente de la carrera de San Jerónimo hasta llegar al paseo del Prado. Sin embargo, la casa del duque de Lerma estaba allí, oculta tras la nueva fachada, hasta que la piqueta terminó con todo aquel complejo edificio a fines del siglo XIX. Así lo revela el detallado y poco conocido plano de toda la posesión del Prado que realizaron Francisco de Cubas y Joaquín de la Concha en 1878 [fig. 1]. ${ }^{12}$ Su presumible exactitud arquitectónica nos informa de modo fehaciente de las medidas de lo construido en el siglo XVII, superando ventajosamente en planta las reproducciones aproximadas de Witt y Teixeira.

La construcción originaria de Gómez de Mora conservaba la estructura de cuatro crujías que rodeaban el gran patio central, aunque quizá no la distribución de las habitaciones. No existían pasillos interiores, por lo que el recorrido interno implicaba tener que atravesar las diversas salas. Tras la puerta principal a la calle del Prado debió de existir un amplio zaguán con acceso al patio. En el siglo XIX, el zaguán aparece tabicado; en su fondo, a la izquierda, se observa la escalera principal, de un solo tiro. En ese lado, el patio central conservaba la galería porticada que originariamente debió rodearlo, cerrada en los otros tres lados para construir habitaciones. Al fondo de la construcción, a la derecha, se halla la pequeña escalera que daba acceso a una tribuna con dos aperturas, desde la que se veía el presbiterio de la iglesia del convento de San Antonio y donde el

\footnotetext{
${ }^{9}$ Muñoz de la Nava Chacón, 2015: 855-920.

${ }^{10}$ Colección Khevenhüller-Metsch, castillo de Hochosterwitz (Carintia, Austria). Reproducido y comentado en Muñoz de la Nava Chacón, 2015: 423- 441. Menos interesante es la versión que recoge el Catálogo de la Exposición del Antiguo Madrid, Madrid 1926, n. ${ }^{\circ} 348$ (con ilustración). comentada en Muñoz de la Nava Chacón, 2015: 416-423, actualmente en la colección de los marqueses de Santa Cruz, fundación Álvaro de Bazán.

${ }^{11}$ Lopezosa Aparicio, 1999: 657-690.

12 Sánchez González, 2017: 285, plano n. ${ }^{\circ} 237$.
} 


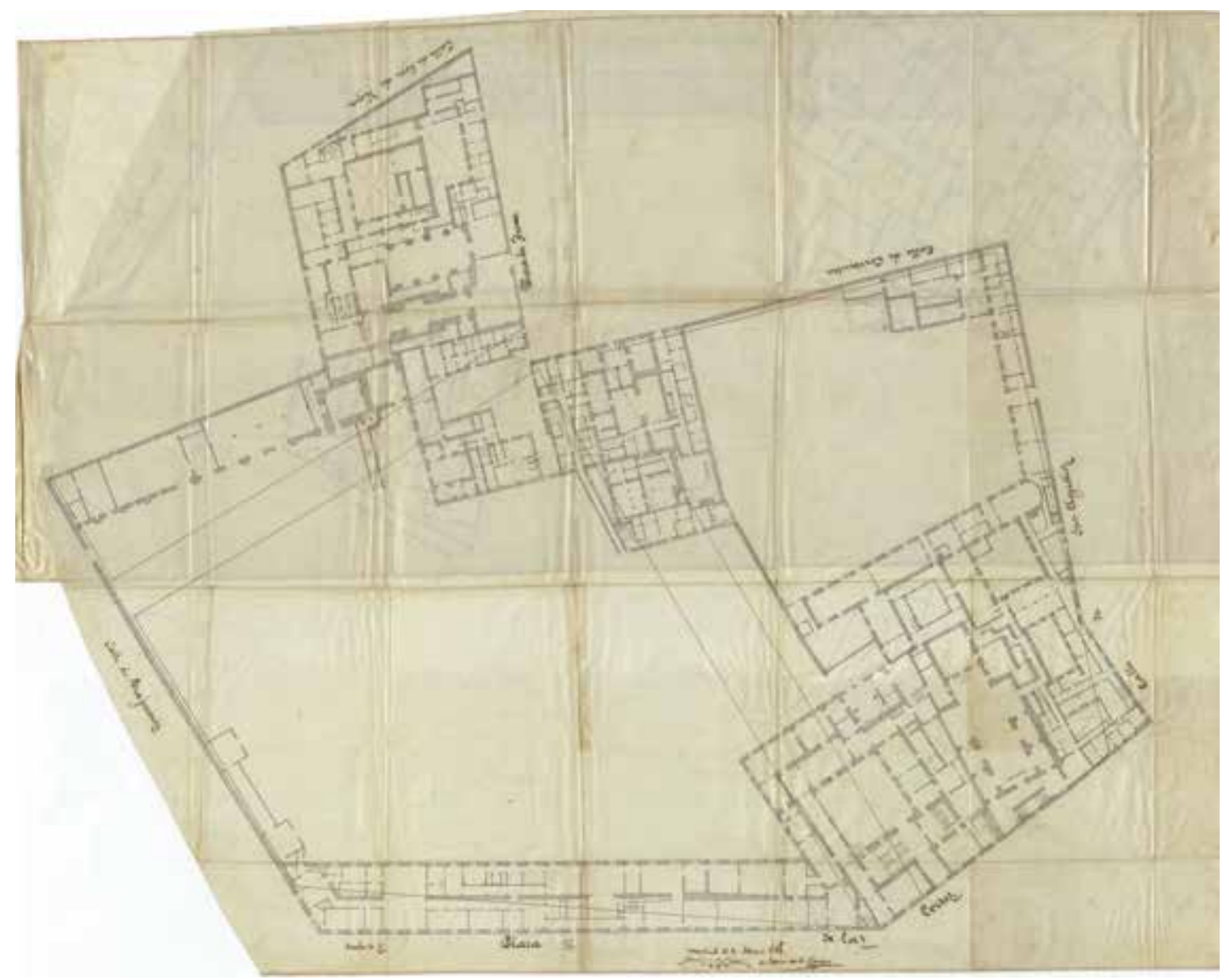

Fig. 1. Planta del palacio del Prado. Francisco de Cubas y Joaquín de la Concha, 1878. Detalle. Archivo Ducal de Medinaceli, Desvinculación, 280-38-1 (Fot. Fundación Casa Ducal de Medinaceli, Sevilla).

duque podía seguir la misa sin salir de su casa. En el extremo de la Carrera que toca al Paseo del Prado, donde antiguamente estuvieron los miradores, se ve una pequeña construcción en ángulo con lo edificado en el siglo XVIII. Había desaparecido, en cambio, engullida por el nuevo edificio dieciochesco, el ala del palacio de Gómez de Mora que se extendía hacia la carrera de San Jerónimo.

Otro importante aspecto que se deduce de este plano es que, a pesar de la apariencia, la superficie que ocupaba la edificación del siglo XVII era al menos tan amplia como la que se añadió en el siglo XVIII, cuyo fondo era muy corto. Así puede explicarse un rasgo tan extraño como que la entrada principal del palacio se abriera en la pequeña fachada a la calle del Prado y no en la larguísima crujía de la Carrera, que tan solo tenía un portón para carruajes.

El palacio conservaba también los jardines con tapias al paseo del Prado en lo que quedó libre de la Huerta del duque de Lerma después de que la recortara de forma considerable en favor de sus fundaciones del convento de Jesús de trinitarios y de San Antonio de capuchinos. Toda la posesión inicial, incluidos los dos conventos y sus huertos, se registraron en la Planimetría General de Madrid — realizada a mediados del siglo XVIII — como una única manzana, la 233.

\section{El palacio del Prado o de Medinaceli}

La finca entró en poder de la familia de los duques de Medinaceli tras el matrimonio del VIII duque, Juan Francisco de la Cerda, con Catalina de Aragón y Cardona, duquesa de Segorbe y Car- 


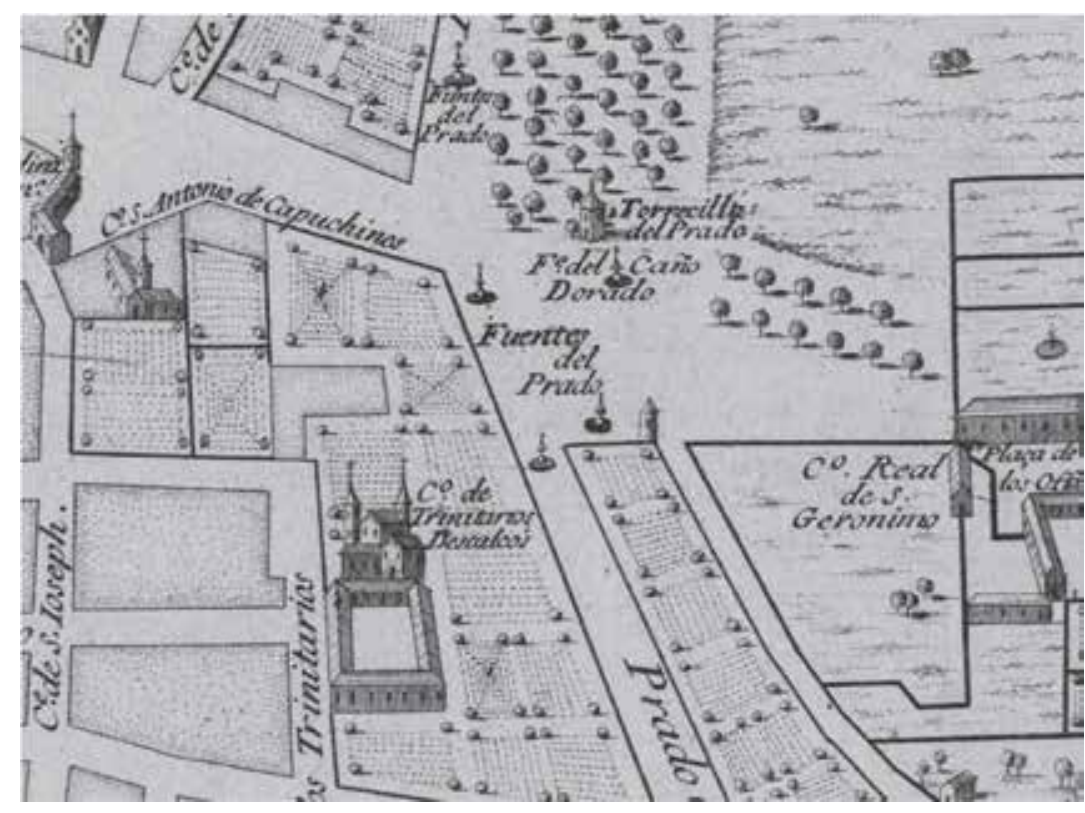

Fig. 2. Plano de Madrid. Nicolas de Fer, París, 1706. Detalle del palacio del Prado (Fot. Comunidad de Madrid).

dona, que heredó en 1659 el ducado de Lerma a la muerte de su hermano Ambrosio, que lo tenía por herencia de su madre, la III duquesa de Lerma, Mariana de Sandoval y Rojas.

La casa del duque de Medinaceli debía de tener a principios del siglo XVIII un aspecto parecido al que le dio Gómez de Mora. Cuando se produjo la muerte de la reina María Luisa de Saboya el 14 de febrero de 1714, el rey y sus hijos se trasladaron allí por deseo de la princesa de los Ursinos. ${ }^{13}$ Llegaron algo antes de la Semana Santa. ${ }^{14}$ Saint-Simon la califica como una de las más bellas casas de la Corte, pero destaca que fue su tamaño reducido lo que impulsó a la princesa a aconsejar el traslado, pues deseaba aislar al rey de sus cortesanos para mejor controlar su voluntad y difícilmente hubiera podido explicar ese aislamiento en el palacio real. ${ }^{15} \mathrm{La}$ estancia acabó ese mismo año, tras haber decidido la princesa que el rey contrajera nuevo matrimonio.

El plano de Nicolás Le Fer, de 1706, señala una silueta para la casa con la misma extensión y situación que en la época de Lerma [fig. 2]. Antonio Ponz se refirió a la importante colección de obras de arte que el duque difunto - el XI duque - había traído de Sevilla, y después de comentar su excelencia, indica: "La bella situación de esta casa está pidiendo un Palacio de buena, y magnífica arquitectura" ${ }^{16} \mathrm{El}$ erudito había afirmado algo antes que las casas de los grandes en Madrid solo se distinguían de las otras en su tamaño.

No se han descubierto documentos relativos a la transformación del antiguo palacio de Lerma en el palacio de Medinaceli. Hasta ahora se ha dado importancia, como si de esa obra se tratara, al proyecto elaborado en 1793 por Manuel Bradi, maestro de obras aprobado por la Real Academia. ${ }^{17}$ No obstante, se trata de una reforma no demasiado significativa.

Afortunadamente, contamos con una imagen del palacio, anterior en cuatro años a la reforma que realizó Bradi. Entre el 21 y 23 de septiembre de 1789 se celebraron grandes fiestas por la exaltación al trono del nuevo rey Carlos IV y jura del príncipe Fernando. Con tal motivo, las

\footnotetext{
13 Saint-Simon (1857): 28.

${ }^{14}$ Saint-Simon (1857): 36: "El domingo de Pasión, 18 de marzo, el rey tuvo Consejo de Estado después de la misa, cenó en el pequeño convento, oyó el sermón y volvió a su casa...".

${ }^{15}$ Saint-Simon (1857): 40: "El pretexto de la muerte de la reina le sirvió para acentuar esta soledad y la retirada al palacio de Medinaceli prefiriéndolo al del Buen Retiro valió para apretarla más, pues era un lugar infinitamente menos amplio que el palacio real, donde la corte podía abundar...”.

16 Ponz (1776): 331.

${ }_{17}$ AVM, Secretaría, 1-53-2.
} 


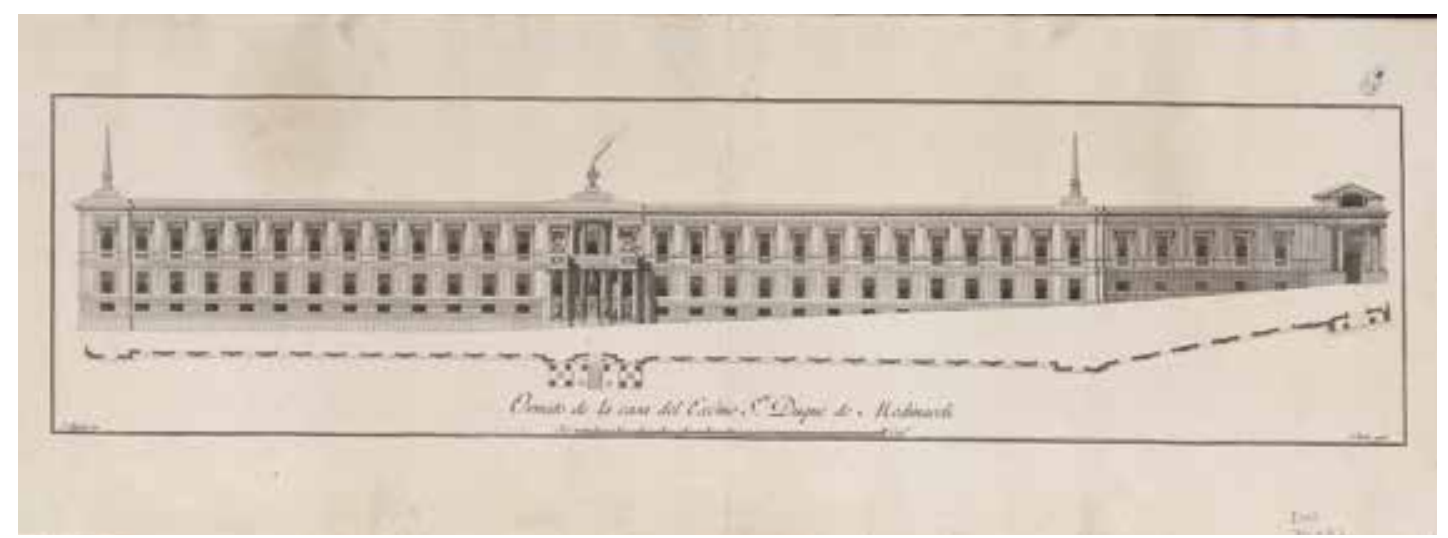

Fig. 3. Ornato de la casa del Duque de Medinaceli. Antonio López Aguado (dibujante) y Francisco de Paula Martí Mora (grabador), Madrid: Imprenta Real, 1789. BNE, Invent/70882 (Fot. procedente de los fondos de la Biblioteca Nacional de España).

casas de los más grandes nobles de la Corte se engalanaron espléndidamente, entre ellas la del duque de Medinaceli. Sempere y Guarinos publicó una relación de los ornatos, ilustrando la obra con estampas dibujadas por los autores de cada invención. ${ }^{18}$ El diseñador del ornato del palacio Medinaceli había sido el joven y recién designado académico de mérito Antonio López Aguado, que proporcionó para la edición dos dibujos, una vista general del palacio adornado y otro con el detalle del fingido atrio con columnas y pinturas que dispuso en el centro de la fachada a la carrera de San Jerónimo. Ambas fueron grabadas por Francisco de Paula Martí Mora [fig. 3]. ${ }^{19}$

Sempere recogió algunos datos sobre el palacio de Medinaceli que debió de proporcionar le López Aguado: "Sus dos fachadas que componen la dilatada línea de quinientos setenta y ocho pies, forman un ángulo muy obtuso; y con esta circunstancia local se junta la de tener la parte que cae a la Carrera, con diez y seis pies de desnivel hacia el Prado". ${ }^{20}$

La verdadera imagen del palacio en 1789 no puede deducirse de la estampa anterior: "Esta portada [la de la calle del Prado] y lo restante de la obra se imitó, con gusto y contraposición, a varias piedras del reyno, por los dos Profesores de Pintura que hicieron los retratos". ${ }^{21}$ José Miconi y Bernardo de Costa, "profesores de la Arquitectura al óleo, temple y demás clases, con especialidad en adornos y figuras", se comprometieron a dar por terminado desde 30 de junio a 15 de septiembre todo el trabajo de pintura y dorado con sus bastidores, lienzo, clavazón, etc. por 119.000 reales, ${ }^{22}$ enorme cantidad que hubiera servido para levantar una buena casa. En la estampa, la estructura del edificio aparece cubierta por lienzos pintados y adornos sobrepuestos de cartón piedra, así almohadillado del zócalo, columnas y pilastras y otros ornamentos entre los vanos, pórtico fingido de la carrera de San Jerónimo y torres simuladas en los extremos. No obstante, la estampa vale para

${ }^{18}$ Sempere y Guarinos, 1789: 43-45 son las páginas que corresponden a la descripción de la casa del Duque.

19 Estampas (sueltas, incluidas en el libro): aguafuerte y buril, tinta china y papel, Madrid, Imprenta Real, 1789. Sempere y Guarinos, 1789: entre pp. 42 y 43: Ornato de la casa del Excmo S. or Duque de Medinaceli. / A Aguado inv.; F. Marti grab. imagen 133 x $538 \mathrm{~mm}$, en hoja de 215 x $615 \mathrm{~mm}$. (Biblioteca Nacional de España, Invent/70882) y entre pp. 44 y 45: Columnario para la estatua equestre de S.M. en casa del Excmo S. ${ }^{\text {or }}$ Duque de Medinaceli / A Aguado inv.; F. Marti grab. imagen 210 x $142 \mathrm{~cm}$. en hoja de 295 x $190 \mathrm{~cm}$.

${ }^{20}$ Sempere y Guarinos, 1789: 43. Según se deduce de la Planimetría General de Madrid, 1988, ad indicem, el sitio 1 de la manzana 233 era el convento de San Antonio, el 2 el palacio Medinaceli y sus jardines y el 3 el convento de Jesús de Trinitarios. Según la escala que figura al pie del dibujo de Manuel Bradi, la fachada a la Carrera de San Jerónimo medía aproximadamente 450 pies y el resto sería la fachada a la calle del Prado.

${ }^{21}$ Sempere y Guarinos, 1789: 45.

22 Pérez Arribas, 1915: 88: "Relaciones de gastos hechos por el duque de Medinaceli y Santisteban para las Fiestas de la exaltación al Trono de Carlos IV, entrada pública con la Reina María Luisa de Borbón y Jura del Príncipe don Fernando [...]". 


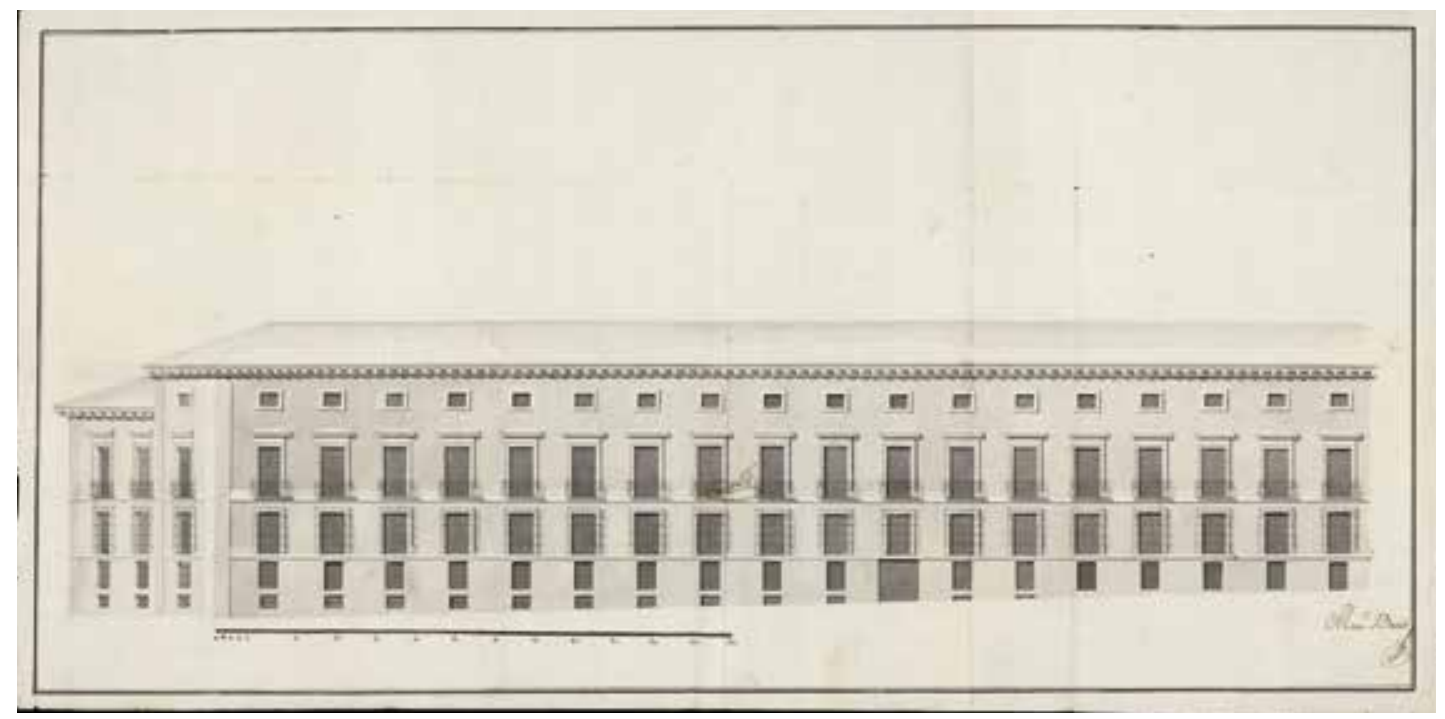

Fig. 4. Ampliación de sotabanco y nueva fachada al paseo del Prado del palacio Medinaceli. Manuel Bradi, 1793. AVM, Secretaría, 1-53-2 (Fot. Archivo de Villa del Ayuntamiento de Madrid).

conocer la longitud del palacio por el lado de la Carrera de San Jerónimo, sus 29 vanos por planta, su escasa dimensión por la calle del Prado, cinco huecos y la puerta. También su altura desigual por el desnivel del terreno, una única planta con balcones en la calle del Prado que se convertía en segunda planta en la Carrera, donde aparecía una primera planta con grandes ventanas y un zócalo que se agrandaba gradualmente hacia el paseo del Prado con ventanas pequeñas y huecos de luces para las bóvedas cada vez más grandes.

La intervención de Manuel Bradi se limitó a elevar la fachada a la Carrera mediante un sotabanco iluminado por pequeñas ventanas rectangulares enmarcadas, y a cerrar por el paseo del Prado las dos crujías que tenía ese palacio, una con fachada a la Carrera y otra con vistas al jardín. En la solicitud firmada el 20 de mayo de 1793 por Juan de Dios Trillo como criado mayor del duque de Medinaceli e "yntendente de las obras que se están construyendo por orden de mi amo", se lee lo siguiente: "Hace presente a V.S. Yltr"ma que en parte de la línea de su fachada principal a la expresada calle [carrera de San Jerónimo] y ángulo que buelbe al Prado quiere S.E. se aumente un sotabanco en su altura, con la elevación que lo muestra el Diseño adjunto para ampliar las avitaciones de su familia de aquel piso..." [fig. 4]. ${ }^{23}$

A su vez, el teniente de maestro mayor de la Villa, Francisco Sánchez, dice en su informe de 15 de junio:

He reconocido la casa que el memorial refiere, y el diseño que para levantar más la fachada se presenta, y lo que se intenta construir de nueva planta por el frente del Prado con motivo de haberse aumentado una crugía por el yinterior, y no hallo inconveniente en que V.S.Y. conceda a esta parte la Licencia que solicita; previniendo convendría quedasen las fachadas conforme manifiesta el Proyecto de la Obra que se intenta hacer en la mayor parte de la fachada principal....

El diseño de Bradi muestra solo 18 vanos de los 29 por planta que tenía la casa a la carrera de San Jerónimo, lo que se explica porque el resto de la fachada era igual. No aparece la vuelta a la calle del Prado con la entrada principal de la casa, pues ahí no se levantaba el sotabanco. ${ }^{24}$ Por el contrario, se representa la forma en que se iban a cerrar las dos crujías del edificio por el paseo del

\footnotetext{
${ }^{23}$ AVM, Secretaría, 1-53-2.

${ }^{24}$ Las reproducciones de la segunda mitad del siglo XIX muestran esa planta superior por la calle del Prado, pero había existido una importante reforma en 1856.
} 
Prado, la de atrás recién hecha, según insinúa Francisco Sánchez. Era más ancha que la antigua - así Bradi adjudica a la crujía trasera dos huecos en cada planta y solo uno a la delantera-; en cambio, la nueva era más baja, pues no se añadía el sotabanco. Ahora bien, si prescindimos de esas novedades, el dibujo de Bradi nos muestra lo que estaba hecho - pensamos- desde los tiempos del XI duque.

Se conocen intervenciones de maestros de obras de escasa relevancia relacionadas con la evacuación de aguas residuales en $1715^{25}$ y en 1757, obra esta última que realizó Juan Antonio de Castro. ${ }^{26}$ Este maestro se excusaba en 1768 de formar parte de una comisión municipal porque estaba trabajando para el duque de Medinaceli. ${ }^{27}$ Pero no lo hacía en el palacio del Prado, sino en el de Atocha.

Se ha escrito que "en 1759, los duques de Medinaceli decidieron renovar la fachada de las viviendas por la calle del Prado y de los Fúcares (antes San José), según los planes, no localizados, de Blas Rodríguez. Aunque nos conste la intervención desconocemos el alcance y envergadura de las obras". ${ }^{28}$ Un examen detallado del expediente pone de manifiesto que el peticionario no era un Medinaceli, sino el duque de Uceda. El proyecto, además, no se debe a Blas Rodríguez sino al maestro de obras Jerónimo Álvaro. ${ }^{29}$ Más tarde nos ocuparemos de esta casa, que pertenecía a la familia Medinaceli, pero que era una finca distinta.

En cambio, no se ha considerado nunca a efectos de este palacio una noticia que posiblemente tiene trascendencia. Se halla en un documento que estuvo en el archivo de la casa de Medinaceli con un proyecto que llevaba el siguiente título: "Plan del sitio del labadero y noria para hacer diferentes cuartos". ${ }^{30} \mathrm{Al}$ parecer, era un plano sobre papel, coloreado y manuscrito de 25 x 25 cm, firmado por el "maestro Corona", fechado en 1762 y que se describe por el archivero, que lo clasificaba como "planta del palacio del Prado de Madrid". El plano no ha sido publicado, a diferencia de otros muchos que existen en el archivo de Medinaceli, por lo que pensamos que se ha extraviado. ${ }^{31}$ A pesar de ello, la reseña parece suficiente para dar alguna luz al problema, pues, esos "diferentes cuartos" podrían ser la edificación del nuevo edificio de la carrera de San Jerónimo, que, como muestra el plano de Cubas, era muy estrecho, apenas una línea de habitaciones.

Los que se han ocupado de este archivo tampoco han identificado al "maestro Corona", que ha de ser, sin duda, el arquitecto real Manuel López Corona (1710-1771), pues firmaba solo y siempre con su segundo apellido. Su trabajo al servicio de las obras reales se documenta ya en 1739. ${ }^{32}$ En 1741 tenía título de arquitecto de las obras del real sitio del Pardo donde construía la casa de los Oficios con un estilo sencillo y funcional. ${ }^{33}$ Allí siguió sirviendo hasta su muerte como prueba la casi decena de anuncios que puso en la prensa durante agosto y septiembre de 1771 para devolver unas alforjas con cosas que encontró en el camino del Pardo y que debían recogerse en su casa de la calle de los Fúcares, junto al Convento de Jesús Nazareno. ${ }^{34}$ Era alarife de Madrid en $1743,{ }^{35}$ en cuya calidad trazó un temprano y conocido proyecto de reforma del paseo del Prado en 1744 y dirigió las obras del cuartel de Conde Duque desde 1742 hasta $1753 .{ }^{36}$ Coincidió con Francisco Carlier en el Pardo en

${ }^{25}$ Lopezosa Aparicio, 1999: 688-689. Licencia para conducir los desagües a la alcantarilla del Prado.

${ }^{26}$ Gili Ruiz, 2017: 335-336.

${ }^{27}$ Agulló Cobo, 1983: 187.

${ }^{28}$ Lopezosa Aparicio, 1999: 689, nota 30.

${ }^{29}$ AVM, Secretaría, 1-45-106.

${ }^{30}$ Fundación Casa Ducal de Medinaceli, Archivo Ducal de Medinaceli (ADM), Archivo Histórico, legajo 222, ramo 28, n. $^{\circ} 1$.

${ }^{31}$ Sánchez González, 2017: 478, n. ${ }^{\circ}$ de catálogo 626. No incluye reproducción del plano, con la observación siguiente: "No localizado el original por desnaturalización de la sección Archivo Histórico". Posiblemente se basa en la ficha del documento.

${ }^{32}$ Lopezosa Aparicio, 2019. Las referencias de licencias municipales de obras de este arquitecto aparecen en la publicación.

33 Tovar Martín, 1991-1992: 191 y fig. 7.

${ }^{34}$ Diario noticioso, curioso, erudito y comercial público y económico, 17, 21, 25, 26, 28 y 30-VIII-1771; 5, 6 y 7-IX-1771, p. 4.

${ }^{35}$ Gili Ruiz, 2017: 340.

${ }^{36}$ Marín Tovar, 2000: 211-212. 


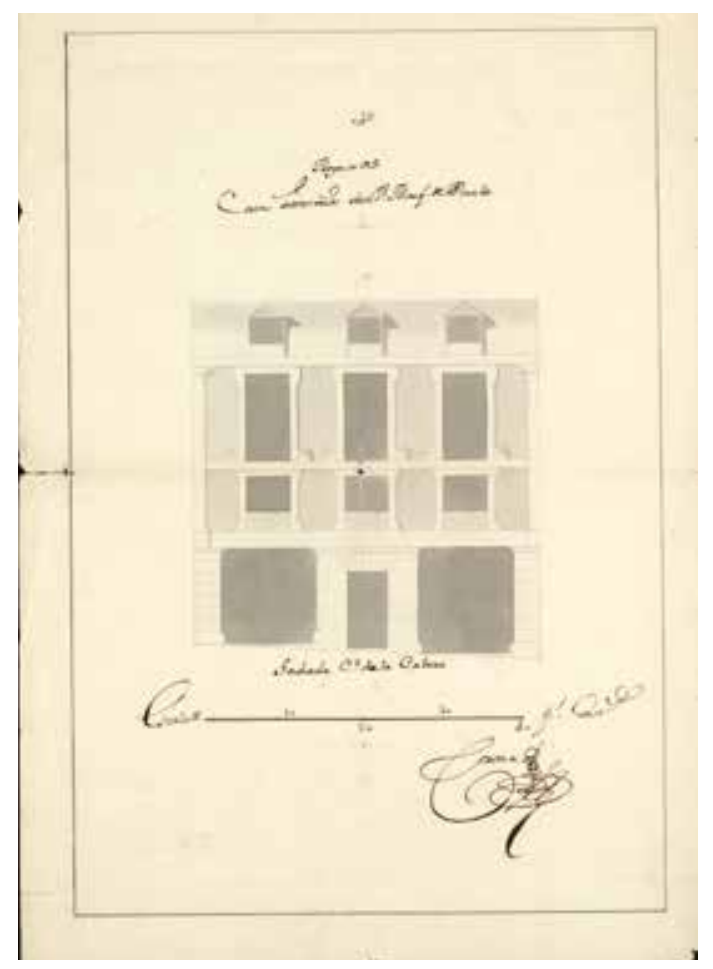

Fig. 5. Proyecto de casa accesoria del marqués de Perales en la calle de la Cabeza. Manuel López Corona, 1758. AVM, Secretaría, 1-45-131 (Fot. Archivo de Villa del Ayuntamiento de Madrid). los primeros años de la década de los cuarenta, trabajando cada uno, al parecer, con independencia del otro. ${ }^{37}$ Colaboró con los arquitectos reales Santiago Bonavia en la construcción del cuartel de guardias de corps de Aranjuez en 1751, Carlos de Borbón y Jaime Marquet en el palacio de Viñuelas en 1761 y Francisco Sabatini en el Pardo, en la construcción del cuartel del Rey y caballerizas y cocheras (hacia 1765) y casa de Infantes (1770). ${ }^{38}$

Pero su labor no se limitó al ejercicio de estos oficios, pues actuó también como tracista y constructor de numerosas obras particulares en Madrid. Una gran casa de la calle de Leganés para el comerciante Lucas de la Peña recibió licencia el 9 de febrero de $1757^{39}$ y una casa accesoria del marqués de Perales en la calle de la Cabeza el 12 de julio de 1758 [fig. 5]:40 ambas incluyen decoración de los huecos de la fachada con marcos de orejetas e incluso tornapuntas en su parte alta o baja, y disponen sillares muy relevados en esquinas y portadas.

Más contenida en elementos decorativos aparece la casa para Antonio Martínez Salazar en la calle del Gobernador, aprobada en 22 de marzo de $1757 .{ }^{41}$ Otros dos proyectos, en la calle del Fúcar de $1757^{42}$ y en la calle de la Escuadra de $1758^{43}$, no contienen alzados. Unos años después, diseña y dirige una casa para Juan Sáenz de Buruaga en la calle de Fuencarral, aprobada en 30 de marzo de $1762,{ }^{44}$ muy diferente de las anteriores, en ladrillo rojo, con huecos adintelados y dovelados y los balcones con peanas adornadas con cupulillas invertidas. Estos proyectos para casas madrileñas, que se agrupan mayoritariamente en una franja de dos años (1757-1758), impiden cualquier hipótesis de hacerle autor del palacio Medinaceli, pues se alejan del rigor geométrico y de la severidad decorativa que caracterizan a este palacio.

Pero, si no autor del diseño, Manuel López Corona pudo ser su constructor y, en tal caso, nos parece que surge con fuerza el nombre del arquitecto preferido de Carlos III. El rango del XI duque y su presencia continua junto al rey hacen verosímil que pidiera una traza a Francisco Sabatini, que ejecutaría su colaborador; así lo haría en 1785 con el retablo del convento de los Capuchinos del Prado, que ejecutó José de la Ballina. ${ }^{45}$ A partir de la llegada del panormitano a Madrid, López Corona, que había gozado de autonomía en las obras del Pardo, pasó a estar a las órdenes del si-

37 Tovar Martín, 1991-1992: 191. Llegamos a conclusiones opuestas a la de la autora sobre la separación de las competencias de ambos maestros.

${ }^{38}$ Lopezosa Aparicio, 2019.

39 AVM, Secretaría, 1-45-149.

${ }^{40}$ AVM, Secretaría, 1-45-131.

${ }^{41}$ AVM, Secretaría, 1-45-150.

${ }^{42}$ AVM, Secretaría, 1-45-146.

${ }^{43}$ AVM, Secretaría, 1-45-122.

${ }^{44}$ AVM, Secretaría, 1-45-50.

${ }^{45}$ Urrea Fernández, 2019: 80-81. Existe al menos otra ocasión en que Sabatini proporcionó trazas a un criado del rey ayuda de la furriera, don Gil de Castresana, para la ermita de San Antonio que costeó en su lugar natal, Villaluenga, en el valle de Mena, en 1787 (Cruz Yábar, 2003: 386). 
ciliano en una colaboración constante. José Luis Sancho ${ }^{46}$ defiende sin dudar la subordinación de López Corona en obras del Pardo como las caballerizas y cocheras del palacio, el cuartel nuevo de los Guardias de Corps y en la casa de Infantes, hechos por el madrileño con trazas de Sabatini en la década 1760-1770.$^{47}$ Colaboraron también en la Villa, como lo prueba una orden de Esquilache de 17 de mayo de 1761 a Sabatini, para que, con López Corona, propusiera los reparos necesarios en el cuartel de Guardias de Corps de Madrid. ${ }^{48}$

Lo que observamos parece un producto típico del estilo del primer Sabatini en Madrid, quizá de 1762, cuando aparece López Corona trabajando para el duque. Se ha indicado — sin atribuir al panormitano este palacio - que tenía parecido con el primer proyecto para la Aduana de $1769 .{ }^{49}$ Es innegable en cuanto al carácter desornamentado y equidistancia de huecos, pero, sin el amplio almohadillado del zócalo y sin huecos de medio punto, podría estar más cerca del Real Albergo dei Poveri de Nápoles, obra de Ferdinando Fuga, del que tan cercano se sentía Sabatini en los conceptos arquitectónicos. En el palacio del Prado, el zócalo existe únicamente porque se señala con una amplia moldura a modo de imposta que recorre la fachada. Las ventanas de la primera planta - lo mismo que las de la planta baja y huecos de luces de las bóvedas - no se enmarcan siquiera, sino que se tapan por las amplias rejas. El tracista reserva los pocos elementos ornamentales para la planta segunda, donde dispone balcones, habituales en la arquitectura doméstica madrileña, con balaustres de hierro muy simples y los vanos enmarcados con una doble moldura prolongada hacia lo alto en un friso plano y una cornisa o guardapolvos, un modelo que usará Sabatini en el ala añadida en Aranjuez por el lado de la capilla hacia la plaza de las Parejas, en la primera planta de la residencia de los Secretarios de Estado (hacia 1771) y en el más tardío Colegio de Cirugía.

Otro dato más a tener en cuenta, que trasluce la dirección de un arquitecto exigente y de gran autoridad, es que las paredes exteriores del palacio de Lerma y posiblemente de su portada — de la que no parece que haya quedado memoria gráfica - se rehicieran en armonía con el nuevo estilo en que se había construido en la Carrera de San Jerónimo. Durante la segunda mitad del siglo XVIII son numerosos los casos de reedificación de fachadas madrileñas manteniendo la estructura interna, pero la causa habitual era el mal estado de los balcones, aleros y revocos, normalmente unido a exigencias del maestro mayor o de los alarifes. Por el contrario, son muy pocos los ejemplares que conocemos en que la estética fuera el motivo para unificar dos construcciones de distinta época.

Entre los arquitectos españoles del momento, solo José de Hermosilla podría hallarse próximo a este modo de construir. Únicamente conocemos un proyecto de arquitectura doméstica con su firma, la casa de Antonio Álvarez Abreu, marqués de la Regalía, en la calle de Torija de 1755 [fig. 6], ${ }^{50} \mathrm{y}$ la idea que plasma está suficientemente cercana al palacio estudiado. Cabe recordar que un alzado casi idéntico al del palacio del Prado aparece en el proyecto de Ventura Rodríguez para una casa en la calle Nueva de San Isidro, propiedad de esta iglesia, aprobado el 21 de junio de 1774 [fig. 7], ${ }^{51}$ y lo reitera en el diseño — con un piso más — de la casa que traza para la Archicofradía del Santísimo Sacramento de la parroquia de Santa Cruz en la calle de la Montera de este mismo año. ${ }^{52}$ No obstante, consideramos ambos ejemplares más un consecuente del palacio de Medinaceli que un antecedente, pues para esa fecha estaría ya terminado. Sea como fuere, nuestra principal objeción al respecto de ambos arquitectos es que el XI duque de Medinaceli no era un hombre

46 Sancho, 1993: 260-262.

47 En la década de los cincuenta, Sabatini había colaborado con Ferdinando Fuga y Luigi Vanvitelli en Nápoles, y ya en España, propuso que ambos respondieran a una serie de ejercicios didácticos, el primero un cuartel de caballería para 650 caballos en sitio abierto y no irregular, cuestión a la que se refiere Vanvitelli en carta de 18 de junio de 1765, que podría tener que ver con este proyecto para el Pardo (Sambricio, 1979: 435-436).

48 Calatrava Escobar, 1993: 521.

49 Martínez Medina, 1993: 366.

s0 AVM, Secretaría, 1-85-27.

${ }^{51}$ AVM, Secretaría, 1-47-70. El propio maestro mayor daría en 12 de diciembre de 1774 a la Real Colegiata de San Isidro un proyecto semejante para prolongar esta fachada en las casas colindantes (AVM, Secretaría, 1-47-105) estudiado en: Moleón Gavilanes / Ortega Vidal / Sancho (2017): 166-167.

${ }^{52}$ AVM, Secretaría, 1-47-80; estudiado en: Moleón Gavilanes / Ortega Vidal / Sancho (2017), 162-163. 


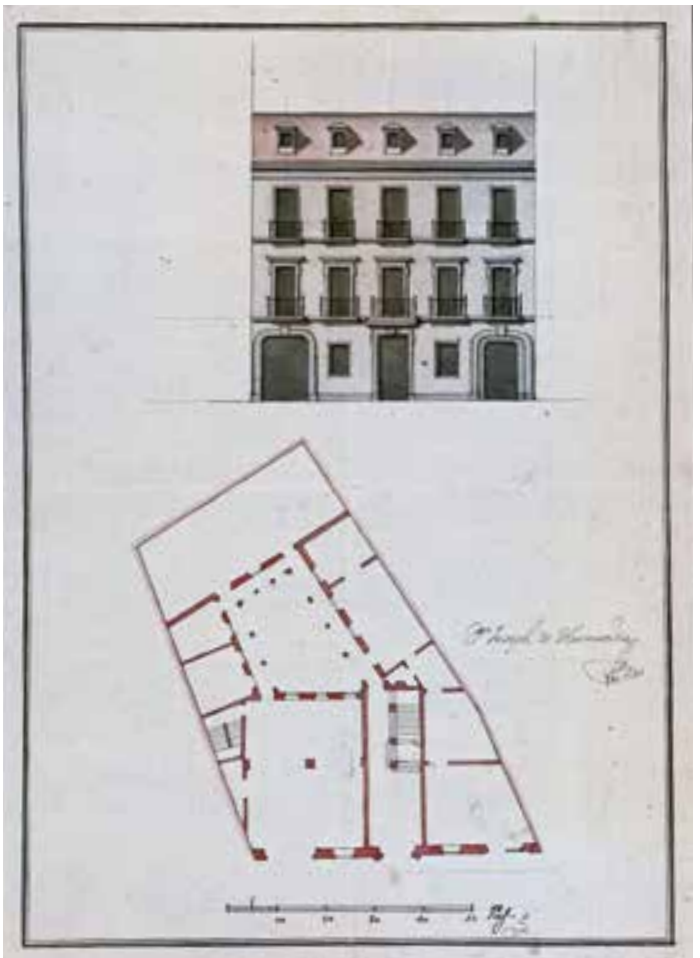

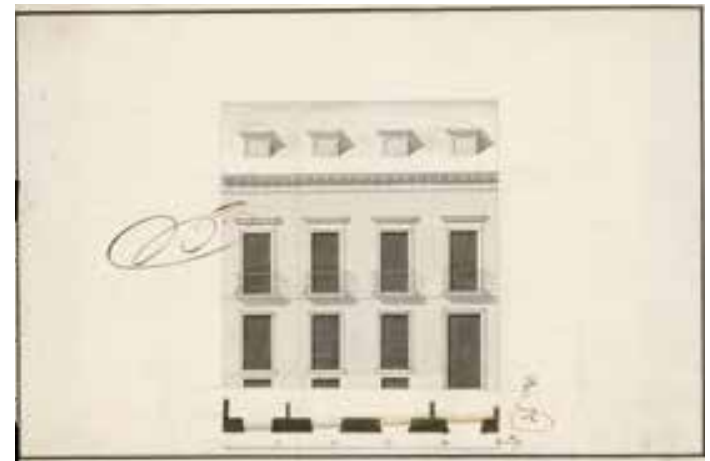

Fig. 7. Proyecto de casa en la calle Nueva de San Isidro. Ventura Rodríguez, 1774. AVM, Secretaría, 1-47-70 (Fot. Archivo de Villa del Ayuntamiento de Madrid).

Fig. 6. Proyecto de casa para el marqués de la Regalía en la calle de Torija. José de Hermosilla, 1755. AVM, Secretaría, 1-85-27 (Fot. Archivo de Villa del Ayuntamiento de Madrid).

próximo a la Academia de Bellas Artes ni al regimiento de la villa de Madrid, sino al rey Carlos III, lo que supone un argumento a favor de Francisco Sabatini que nos parece decisivo.

Con esta atribución esperamos suscitar un debate, hasta ahora inexistente, sobre la autoría de un edificio que tuvo una importancia arquitectónica pareja al menos a la que sus dueños tenían en la sociedad madrileña.

En 1856-1857, este palacio fue reformado por Wenceslao Graviña, que elevó su altura y añadió el falso pórtico que centraba la fachada a la carrera de San Jerónimo con el que ha pasado a la posteridad gracias a haber coincidido con el momento de la difusión de la fotografía. Fue finalmente derribado tras su venta el 17 de abril de 1889.

\section{El palacio de Atocha o de Cogolludo}

El segundo palacio de los Medinaceli en Madrid estuvo destinado a vivienda del heredero del título, al que por tradición correspondía el marquesado de Cogolludo. Fue objeto de tres intentos de renovación en el siglo XVIII, dos frustrados y uno llevado a término.

En 25 de noviembre de 1765, el futuro XII duque, marqués de Cogolludo y Aytona, solicitaba licencia del Ayuntamiento para una obra inmediata a su casa principal en la calle de Atocha. Presentaba un plano firmado por el maestro de obras Juan Antonio de Castro, en que figuraba en una tinta lo que estaba construido y en otra lo que se proyectaba agrandar [fig. 8]. ${ }^{53}$

Había también tres alzados con las nuevas fachadas, dos de ellas, muy largas, por Atocha y Magdalena y otra más corta por Antón Martín [fig. 9].

Debió de ser imposible adquirir los sitios de la manzana 155 necesarios para edificar aquella casa. El plano que distinguía entre lo edificado y lo proyectado demuestra que la fachada del palacio a la calle de Atocha medía 83 pies, mientras tenía por la calle de la Magdalena una línea

\footnotetext{
${ }^{53}$ AVM, Secretaría, 1-44-104.
} 

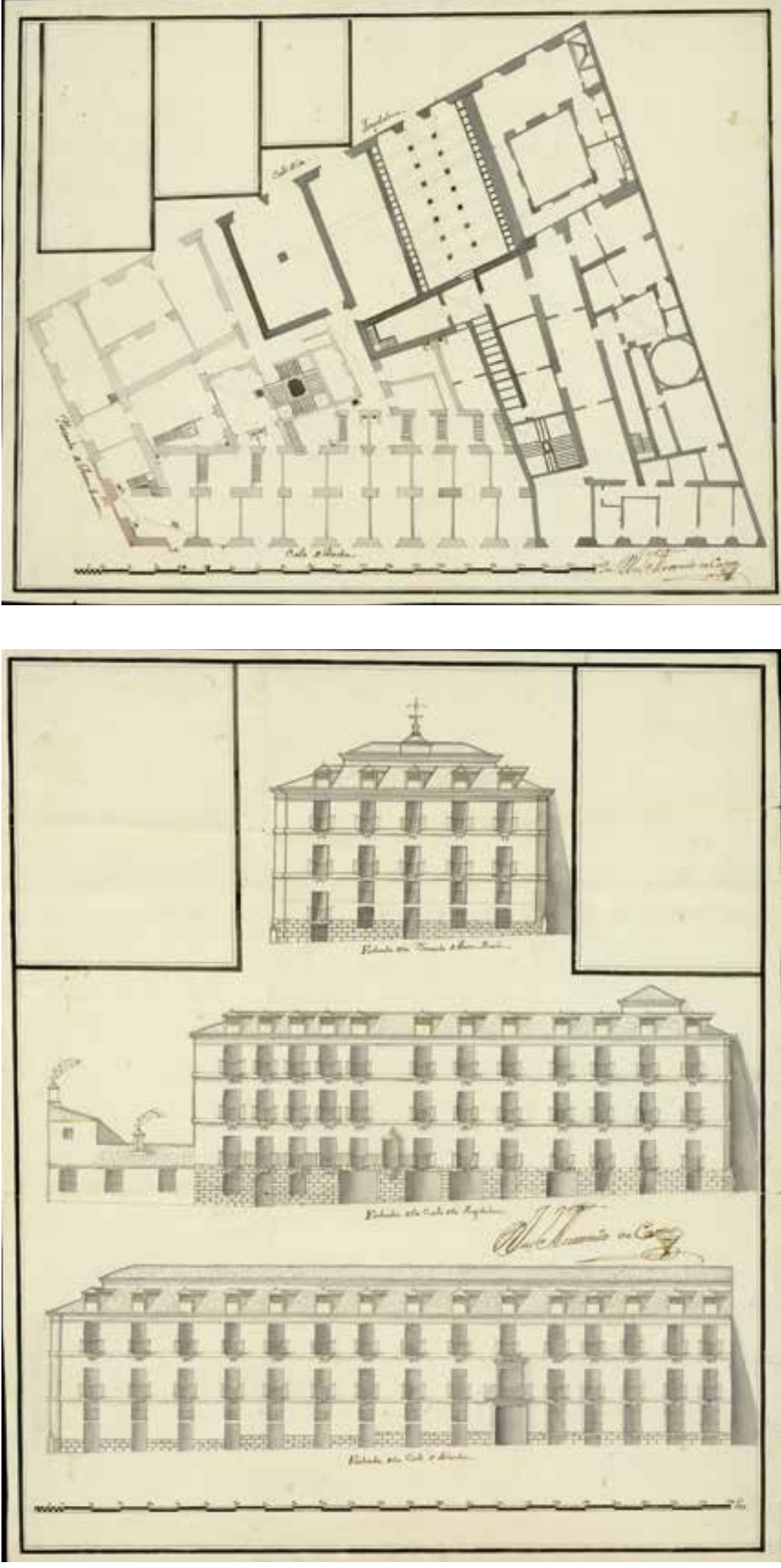

Fig. 8. Proyecto de reforma del palacio del marqués de Cogolludo. Plano de lo edificado y de la obra nueva. Juan Antonio de Castro. 1765. AVM, Secretaría, 1-44104 (Fot. Archivo de Villa del Ayuntamiento de Madrid.
Fig. 9. Proyecto de reforma del palacio del marqués de Cogolludo. Alzado de fachadas a Antón Martín, Magdalena y Atocha. Juan Antonio de Castro, 1765.

AVM, Secretaría, 1-44-104 (Fot. Archivo de Villa del Ayuntamiento de Madrid. 
de fachada casi doble, 161 pies, ocupada por la parte trasera del palacio, una cuadra y una gran cochera. Según la Planimetría, el duque de Medinaceli poseía los sitios 5, 7 y 9 de la manzana 155, el primero con 83 pies a Atocha y 161 a Magdalena, exactamente los que tenía el edificio, y los otros dos con fachada a Atocha de 8 pies el sitio 7 y de $41 \frac{5}{8}$ pies el sitio 9 , pero sin comunicación entre los tres, pues se hallaban en medio el minúsculo sitio 6 con 8 y $1 / 2$ pies, y el sitio 8 con 17 pies. Era preciso adquirir estos dos sitios al menos y alguno más hacia Antón Martín para poder construir el proyecto, cuyas dos fachadas largas medían más de 200 pies. No se edificó, como lo prueba la portada del expediente: "Ex. ${ }^{\mathrm{mo}}{ }^{\mathrm{S}} .{ }^{\text {or }}$ Marq. ${ }^{\mathrm{s}}$ de Cogolludo. Expediente $\mathrm{s}^{\mathrm{re}}$ la rehedificaz" de sus casas de la calle de Atocha, unión a ellas de otras inmediatas y de diferentes pedazos de sitio del Público", y más abajo: "Nota. No tuvo efecto $\mathrm{p}^{\mathrm{r}}$ no haver entregado en Arcas el valor de $\mathrm{d}^{\text {ho }}$ sitio del Público". A las dificultades de adquirir suelo debió de añadirse el hecho de que el 14 de enero de 1768 muriera el XI duque de Medinaceli, con lo que el comitente de esta obra accedió al título y a la propiedad de la posesión del Prado, lo que disminuiría su interés por la casa de Atocha.

Juan Antonio de Castro, alarife de la Villa, firmante del proyecto, había trabajado para el duque a partir de 1757 reparando las alcantarillas del palacio del Prado.$^{54}$ Actuaba en 1767 como alarife en las obras del paseo del Prado que dirigía José de Hermosilla, si bien le sustituyó pronto Francisco Sánchez. ${ }^{55}$ Fue muy activo en la construcción de encargos de particulares y seguía trabajando para los Medinaceli en junio de 1770, cuando Ventura Rodríguez corregía su proyecto para cerrar un atrio en el convento de San Antonio inmediato a la entrada al palacio del Prado, obra que pagaba el duque. ${ }^{56}$

El estilo arquitectónico de Juan Antonio de Castro era muy del gusto de la primera mitad del siglo, cercano a lo rococó. La entrada principal, descentrada - respetaba el lugar que tenía antes de la reforma-, era una gran puerta con balcón amplio encima, ambos moldurados y coronados por un frontón; zócalo almohadillado con ventanas y huecos de luces, dos plantas con balcones alabeados y cupulilla invertida por debajo - semejantes a los de un proyecto de Castro de 1762 para la casa de don Pedro de Castilla en la calle de Leganitos $-{ }^{57}$ y buhardillas. La fachada a Antón Martín, donde el duque no poseía suelos, era mucho más estrecha que las otras dos, añadía una entreplanta con balcones no salientes, dos plantas más con balcones como los de Atocha y buhardillas, y sobresalía del tejado un cuerpo rematado en cruz, que señalaría la capilla. Por último, por la calle de la Magdalena, Castro elevaba tres plantas sobre el bajo, incluidas las cuadras, con balcones como los del palacio y un desván con buhardillas.

Poco debió de hacerse a partir de este proyecto; quizá cambios puramente formales en la fachada hacia Antón Martín que miraba al jardín interior, pero sin extensiones. La escasa longitud del frente del palacio se confirma en la estampa de su ornato para las fiestas de la exaltación de Carlos IV en septiembre de $1789^{58}$ con la decoración que Filippo Fontana ideó para él. ${ }^{59}$

El mismo comitente de 1765, ya XII duque, don Pedro de Alcántara Fernández de Córdoba, promovió en 1788 la única transformación del palacio de Atocha que tuvo efecto. El 3 de septiembre, su administrador pidió licencia para reedificar la fachada a la calle de la Magdalena de la casa que habitaba el marqués de Cogolludo. Presentaba un proyecto de Manuel Bradi, que ya había trabajado antes para la familia del duque.$^{60} \mathrm{~A}$ los 161 pies que tenía a la calle el sitio 5 , se añadía una casilla colindante cuya reedificación incluía en el proyecto [fig. 10] ${ }^{61}$ Debía ser del sitio 10,

${ }^{54}$ VizcaínoVillanueva, 1991-1992: 150. En ese año daba dictamen sobre el estado de la torre de San Salvador.

${ }_{55}$ Lopezosa Aparicio, 1999: 365 y 367.

${ }_{56}$ AVM, Secretaría, 1-47-8.

57 AVM, Secretaría, 1-45-47.

${ }^{58}$ La estampa (suelta e incluida en el libro: Sempere y Guarinos, 1789: entre pp. 28 y 29) fue dibujada por Felipe Fontana y grabada por José Giraldo García: Ornato de la Casa del Excmo. Señor marqués de Cogolludo / F. Fontana inv.; J. Giraldo grab. Madrid, Imprenta Real, 1789. Estampa: aguafuerte y buril, tinta china y papel; imagen $210 \times 340$, en h. de 295 x 420 (BNE, Invent/70879).

${ }_{59}$ Una descripción muy minuciosa del adorno, "BREVE RELACIÓN de lo actuado por el Excmo. Sr. D. Luis María de la Soledad Fernández de Córdoba, Marqués de Cogolludo...”, en Pérez Arribas, 1915: 78-88.

${ }^{60}$ En 1784 había trazado una modificación de la calle llamada de Malpica, donde se hallaba el palacio de la duquesa, frente a Santa María (AVM, Secretaría, 1-50-19).

${ }^{61}$ AVM, Secretaría, 1-55-60. 


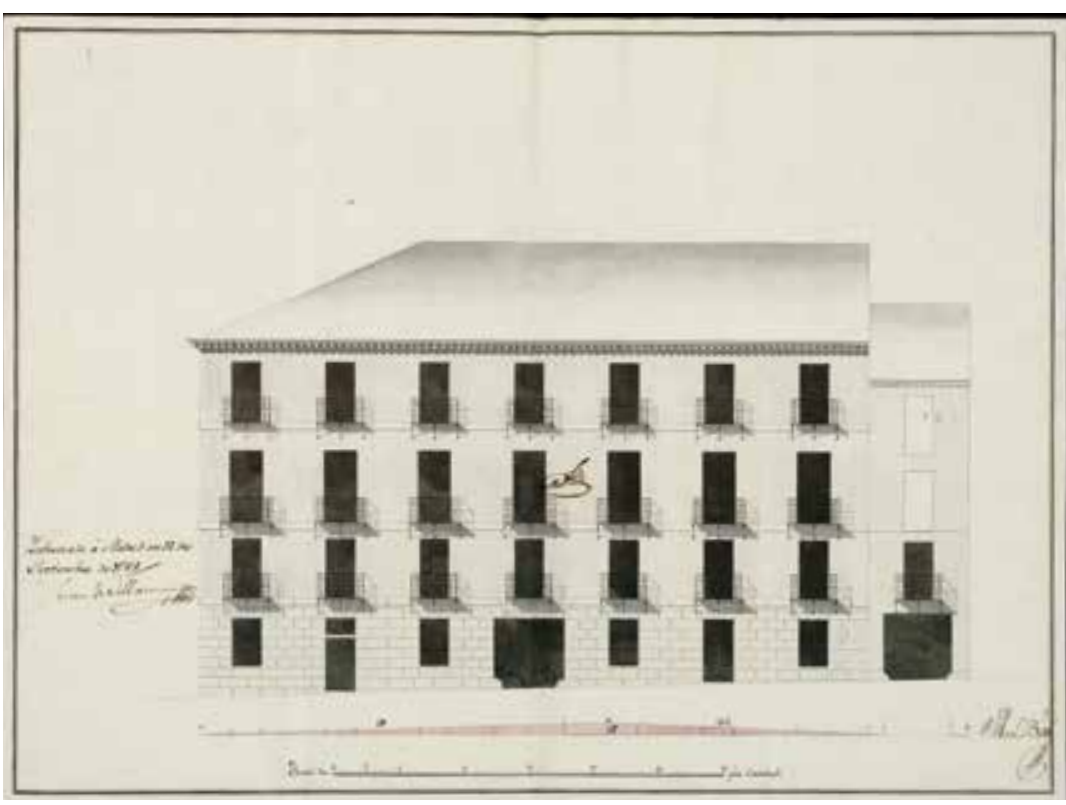

Fig. 10. Proyecto de reforma de la fachada a la calle de la Magdalena del palacio del marqués de Cogolludo. Manuel Bradi, 1788.

AVM, Secretaría, 1-55-60 (Fot. Archivo de Villa del Ayuntamiento de Madrid).

con 15 pies de fachada a la Magdalena y 41 a Atocha y medianería completa con las fincas 9 y 5 , ambas del duque, una compra muy conveniente pues mejoraba las posibilidades de agrandar la fachada principal. Bradi se proponía derribar lo construido por la Magdalena y Juan de Villanueva, maestro mayor de la Villa, aprovechó para enderezar la línea quebrada del frente tomando algo de suelo público, que el duque pagó al ayuntamiento con 2.665 reales.

El proyecto elevaba tres alturas sobre la planta baja, pero la "pequeña casa" se presentaba solo con la planta baja y la principal, aunque Bradi insinuaba en tinta muy diluida dos plantas encima con un balcón en cada una, porque Villanueva deseaba que se unificaran alturas en las casas madrileñas. La fachada es absolutamente funcional, quizá por la condición accesoria de esa parte del palacio, destinada a oficios y habitaciones de la servidumbre que no requería aspecto suntuoso. Su ornamento se reduce a los grandes sillares en toda la altura de la planta baja y las formas de dovela que dispone sobre los dinteles de portones y ventanas. Encima, tres plantas con siete vanos cada una con balcones sostenidos por cartelas de hierro.

Llega en 1800 el diseño más interesante de todos los relacionados con los palacios madrileños de los Medinaceli. El 30 de octubre de ese año, Juan de Dios Trillo, intendente de las obras del XIII duque, solicitaba licencia para que se continuara la obra de la casa que tenía su señor en las calles de Atocha y Magdalena, según los planos que presentaba firmados por Antonio Bradi. ${ }^{62}$ Presentaba dos diseños, uno de ellos la parte de atrás del palacio a la calle de la Magdalena, que no se había de derribar, sino aumentar con unos 40 pies más [fig. 11]. La parte construida es del todo semejante a lo que Bradi proyectó en 1788 y la ampliación se igualaba formalmente con lo ya fabricado. Las cocheras o cuadras, con una sola altura, tenían ahora dos puertas más, quizá construidas en $1795 .^{63}$

El 13 de noviembre acudió Juan de Villanueva para la tirada de cuerdas y señaló lo siguiente:

...he visto y reconocido las alineaciones que deberán observarse para la nueva construcción de fachadas [...] e igualmente he tenido presente quanto con semejantes motivos en una parte de las expresadas fachadas hacia la calle de la Magdalena y otra que provisionalmente se construyó en sus inmediaciones a la frente de la plazuela de Antón Martín expuse a V.S.Y [...] respecto a la casa

${ }^{62}$ AVM, Secretaría, 1-56-42.

${ }^{63}$ En el expediente de licencia se mencionan dos reformas autorizadas en ese año. 


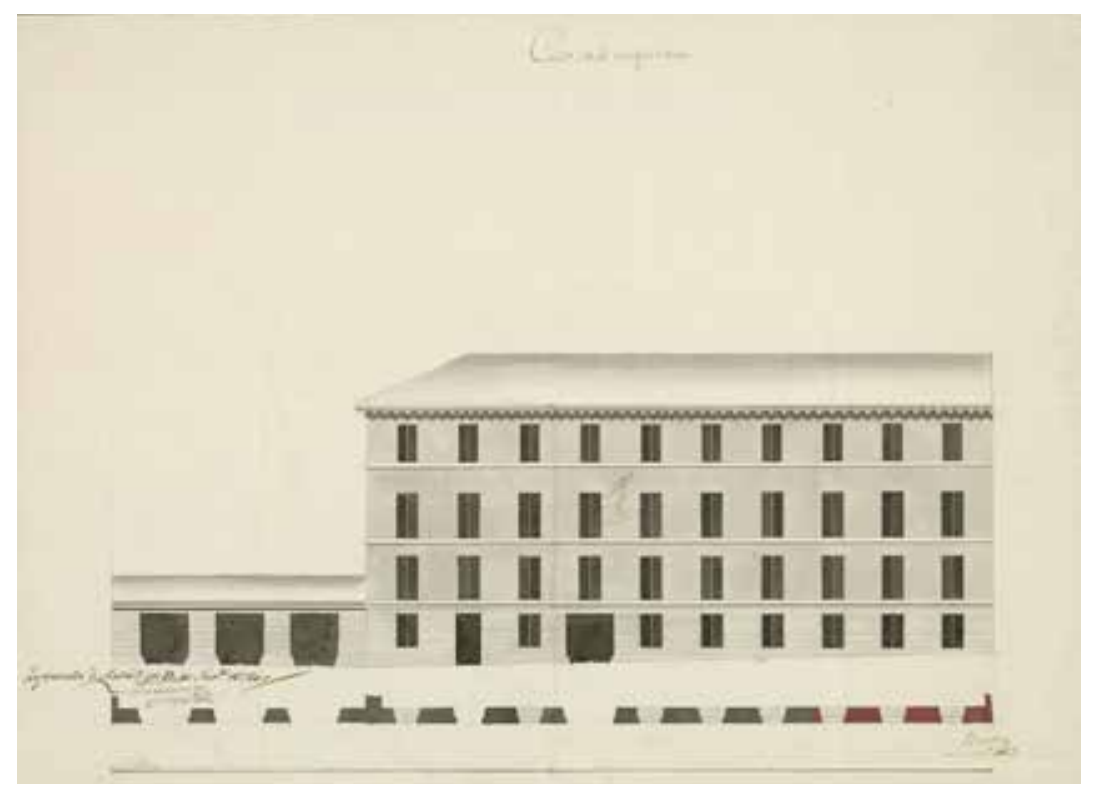

Fig. 11. Proyecto de ampliación de la fachada a la calle de la Magdalena del palacio del marqués de Cogolludo. Manuel Bradi, 1800. AVM, Secretaría, 1-56-42 (Fot. Archivo de Villa del Ayuntamiento de Madrid).

baxa con medianera a la nueva construcción que ahora se intenta [la ampliación de 40 pies] [...] mediante la buena disposición con que parece se encuentra el Excmo Sr. Duque de Medinaceli para verificar la completa adquisición de aquellas infelizes y deterioradas casas $[\ldots]{ }^{64}$

Villanueva trataba continuamente de animar al duque a adquirir más casuchas para dignificar el caserío de la zona.

La firma de Antonio Bradi, sobrino de Manuel, no nos debe apartar de la idea de que fue este último quien lo ideó. ${ }^{65}$ Además de sus múltiples trabajos para los Medinaceli, hay testimonio de que tenía la consideración de arquitecto de los duques ${ }^{66}$ En otra publicación que hemos dedicado a este interesantísimo maestro de obras,${ }^{67}$ demostramos que Antonio Bradi fue un aparejador que actuó en las obras reales hasta que, en 1795, un choque con Villanueva forzó su despido, lo que coincidió con un desgraciado derrumbe en enero de 1796 de una casa que construía su tío Manuel, que dio lugar a una causa criminal en el Real Consejo. Quizá alguna interdicción de ejercer determinó que Antonio firmara en su lugar durante cerca de diez años.

El diseño que estudiamos tiene por la línea de Atocha 203 pies, una extensión que, a diferencia de lo que ocurría en 1765, estaba ya disponible por ser ya propietario el duque de los sitios 5 a $10 .{ }^{68}$

La fachada a Atocha que diseña Bradi es un hermoso palacio que destaca por su trazado armónico, regular y de gran elegancia [fig. 12], con un pórtico apenas sobresaliente en volumen y altura y dos alas que se estrechan visualmente en los extremos con dos cuerpos ligeramente adelantados y resaltados por molduras.

La planta baja es de sillares almohadillados con ventanas enrejadas y pequeños huecos de luces bajo ellas, separada por una imposta del resto de la fachada. Grandes balcones con

${ }^{64}$ AVM, Secretaría, 1-56-42.

${ }_{65}$ Navascués, 1975: 134. Fue el primero en destacar la importancia de este palacio, aunque no menciona el hecho de que era Antonio Bradi quien firmaba la traza.

${ }^{66}$ Pérez Arribas, 1915: 88. En la partida relativa al pago del ornato de 1789 del palacio Medinaceli a los pintores, consta lo siguiente: "Visto el plano ejecutado por D. Antonio Aguado, Académico y Arquitecto, y visado por el [arquitecto] de la Casa de Medinaceli, D. Manuel Bradi".

${ }^{67}$ Cruz Yábar, 2021.

${ }^{68}$ Según la Planimetría, estos sitios tenían de fachada a Atocha los siguientes pies: sitio 5, 83 y 3/4; sitio 6, 8 y 1/2; sitio 7,8 ; sitio 8,17 ; sitio 9,41 y $5 / 8$; sitio 10,41 . 


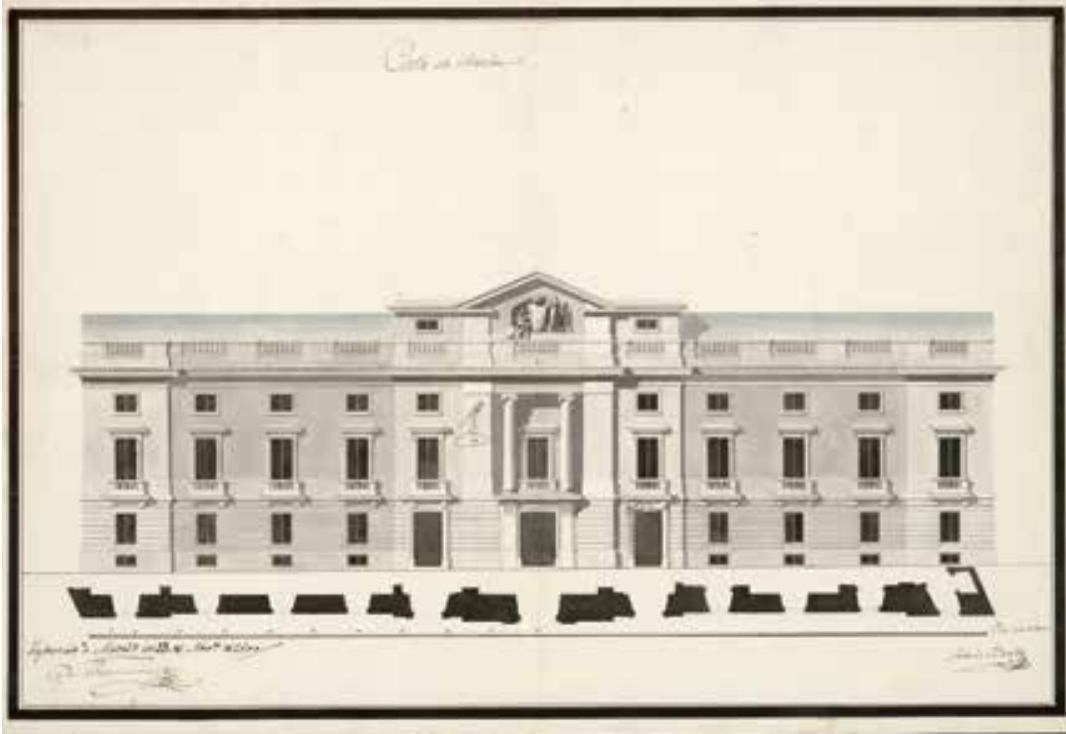

Fig. 12. Proyecto de reforma de la fachada a la calle de Atocha del palacio del marqués de Cogolludo. Manuel Bradi, 1800. AVM, Secretaría, 1-56-42 (Fot. Archivo de Villa del Ayuntamiento de Madrid).

balaustres de piedra en la planta principal rematados por cornisas, sostenidos por ménsulas y rodeados por una moldura plana. Piso superior a modo de sotabanco con pequeñas ventanas apaisadas y rodeadas de moldura plana. Toda la fachada remata en una baranda que alterna machones y balaustres de piedra. La mayor y mejor novedad radica en el cuerpo central, que Bradi organiza hábilmente en dos alas laterales poco salientes respecto al resto de la fachada, con la que se integra por la continuidad del tamaño, forma y altura de los balcones y ventanas, y una parte central que avanza ligeramente, conectada con las alas exteriores por la misma altura de las puertas que se abren en la parte baja. Una lleva encima guirnaldas de flores en lo alto como posible variante. La puerta central queda flanqueada por dos anchas pilastras de capitel estriado que sostienen un gran balcón situado en un recuadro excavado y en su interior dos enormes columnas apoyadas en unas cartelas y con capitel jónico, adaptación de la idea de Juan de Villanueva para el pórtico del oratorio de Caballero de Gracia, según apuntó Navascués. ${ }^{69}$ Encima, un pequeño cuerpo con dos cortas alas terminadas en cornisas y en el centro un frontón con gran escudo ducal en su interior sostenido por dos figuras femeninas, una arrodillada mostrándolo y otra de pie apoyada en él.

Frente a este elegante y suntuoso modelo de casa nobiliaria en la Corte, no podemos por menos de recordar su contraste con los dos severos edificios construidos como casas de jornada en El Escorial y Aranjuez. Fue también su comitente el XIII duque, que encargó los proyectos a Juan de Villanueva hacia 1785 y $1793,{ }^{70}$ respectivamente.

Este magnífico proyecto pasó al olvido, seguramente, al fallecer el XIII duque en 1806. Los sitios 6, 7, 8, 9 y 10 con fachada a la calle de Atocha, que tenían que haber servido de suelo a la ampliación del palacio, se vendieron antes de 1832 a don Gaspar de Soliveres, que los edificó en este año según proyecto de Francisco Xavier de Mariátegui. ${ }^{71}$

${ }_{69}$ Navascués, 1975: 135. El proyecto es de 1782 (Museo de Historia de Madrid), aunque no se construyó hasta 1820 por Custodio Moreno. Tiburcio Pérez Cuervo utilizará el modelo en el Colegio de Medicina y Cirugía de San Carlos de 1834-1836 (Moleón Gavilanes, 2019: 244).

${ }^{70}$ Arquitectura y desarrollo urbano: Comunidad de Madrid, 1998: 412-414 y 2004: 572-576, respectivamente.

${ }^{71}$ AVM, Secretaría, 1-63-101. La fachada medía 133 pies. 


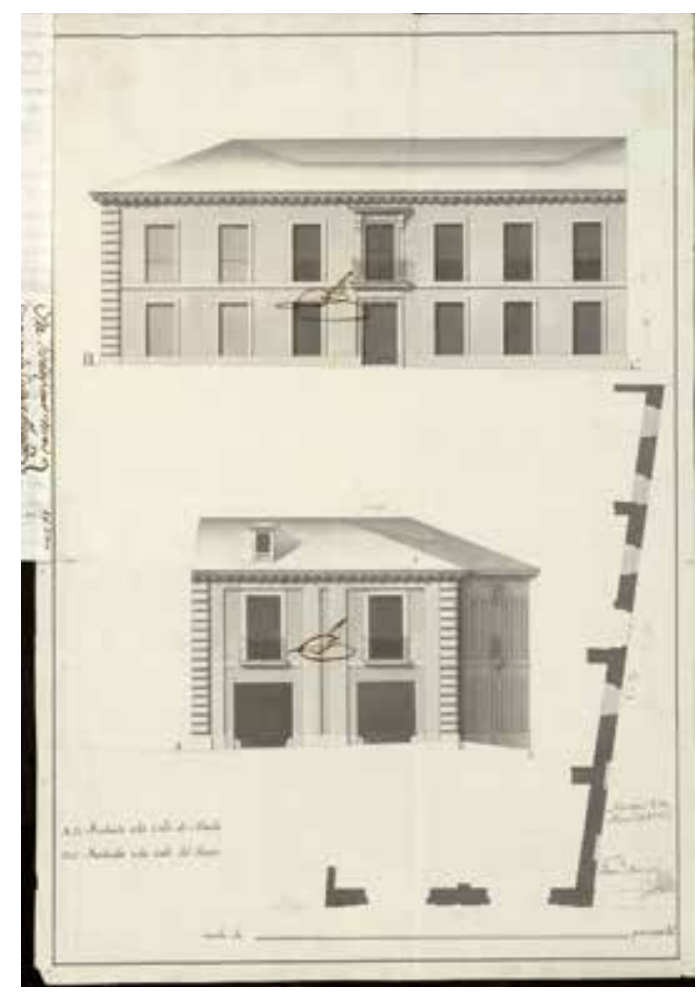

Fig. 13. Proyecto de edificación de nueva planta de la casa de los duques de Medinaceli en la calle del Turco con vuelta a Alcalá. Francisco Sánchez, 1783. AVM, Secretaría, 1-4997 (Fot. Archivo de Villa del Ayuntamiento de Madrid).

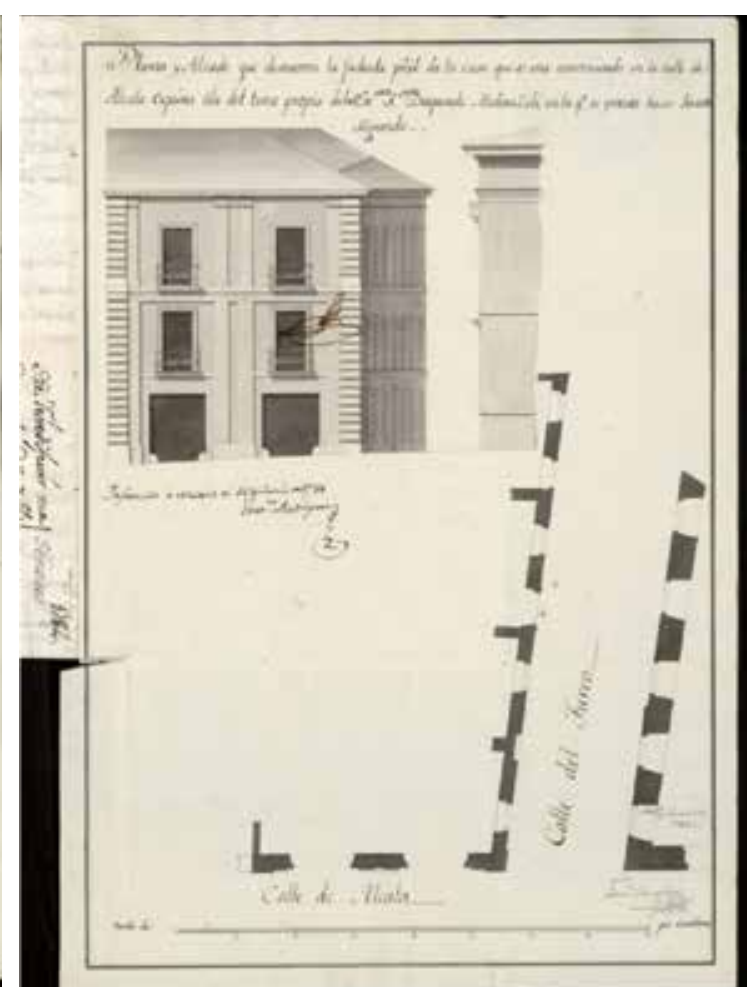

Fig. 14. Proyecto de elevación de una planta en la casa anterior. Francisco Sánchez, 1784. AVM. Secretaría, 1-49-125 (Fot. Archivo de Villa del Ayuntamiento de Madrid).

\section{Dos casas de las duquesas viudas cercanas al Paseo del Prado}

Solo haremos una breve referencia a ellas, pues alguna vez se han confundido con el palacio estudiado en el punto I.

La duquesa viuda doña Jerónima Espínola adquirió una posesión de importante superficie en la calle del Prado, donde se hallaba la casa principal, con vuelta a Júcar. ${ }^{72}$ En marzo de 1743 pidió licencia para edificar en esta última calle, enfrente de la puerta de carros del convento de capuchinos, unas caballerizas y tres cocheras con una planta principal y buhardillas según un diseño firmado por José Arredondo que no se halla en el expediente. ${ }^{73}$ Aunque el regidor comisario señaló que la calle tenía 17 pies de ancho en la parte de las cocheras y 21 en las caballerizas y formaba un ángulo saliente, no se obligó a la duquesa a alinear las fachadas. Tras su muerte en 1757 pasó a habitar la casa el duque de Uceda, cuyo palacio había sido arrendado al rey en 1717 para alojar a los Consejos. Su mayordomo solicitó licencia el 6 de marzo de 1759 porque "la casa que avita su Ex cia sita en la calle de el Prado" necesitaba reparos y terminar la escuadra que llegaba a la calle del Júcar. ${ }^{74}$ El informe de 1743, instado por doña Jerónima, hablaba de "otras cassas que dicha Exma $\mathrm{S}^{\text {ra }}$ tiene inmediatas a la Prâl de la calle del Prado las quales no están lavradas al piso correspon-

\footnotetext{
72 Esta calle se llamó antes de San Joseph, después del Júcar y, ya en 1759, se afirma que se llamaba San Agustín, nombre que actualmente conserva. La calle del Fúcar, cercana a ella, se iniciaba en el convento de trinitarios de Jesús y acababa en Atocha.

${ }_{73}$ AVM, Secretaría, 1-84-34. Era el sitio 6 de la manzana 227, de 41.432 1/2 pies superficiales, comprado recientemente por la duquesa viuda, que privilegió el 13 de febrero de 1744 tres sitios de los nueve que lo componían.

${ }^{74}$ AVM, Secretaría, 1-45-106.
} 


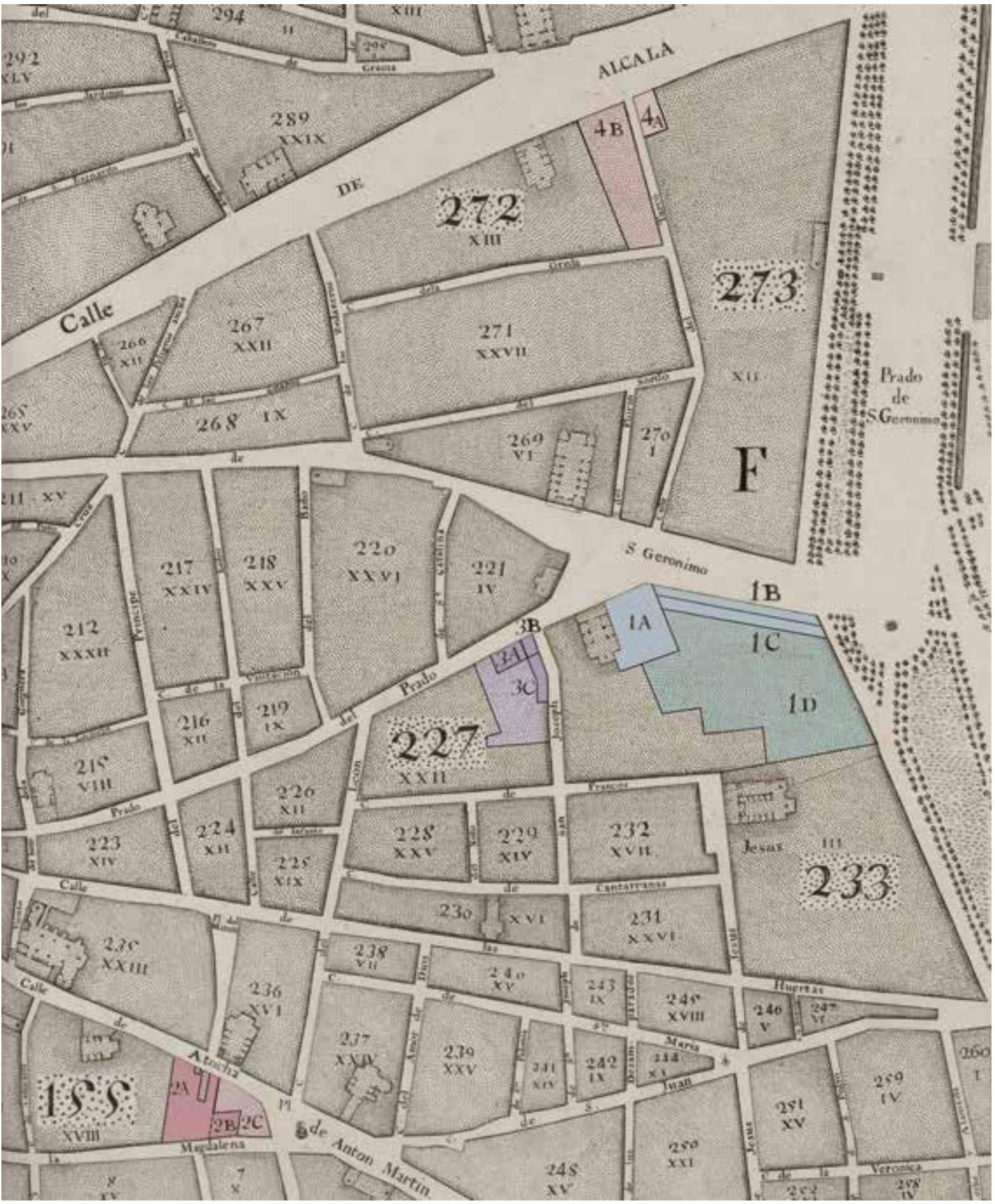

Fig. 15. Plano de Madrid. Antonio Espinosa de los Monteros, 1769. Ubicación y detalles de los Palacios:

- Manzana 233. Palacio del Prado: 1A. Casa del duque de Lerma. Juan Gómez de Mora, (1614). 1B. Primera crujía de la ampliación ¿Francisco Sabatini y Manuel López Corona (h. 1762)? 1C. Segunda crujía de la ampliación. Manuel Bradi (1793). 1D. Jardines.

- Manzana 155. Palacio de Cogolludo: 2A. Palacio edificado según el plano de Juan Antonio de Castro (1765). 2B. Reedificación y ampliación de la fachada a la calle de la Magdalena. Manuel Bradi (1788). 2C. Solares necesarios para realizar los proyectos de Juan Antonio de Castro (1765) y Manuel Bradi (1800).

- Manzana 227. Posesión de Da Jerónima de Espínola, viuda del X duque: 3A. Casa principal. 3B. Elevación de la esquina de la casa principal. Jerónimo Álvaro (1759). 3C. Casas accesorias. José de Arredondo (1743). Resto punteado y más claro: jardines.

- Manzana 273: 4A. Casa de Da Petronila de Alcántara Pimentel y Cernesio. Francisco Sánchez (1783 y 1784). Manzana 272: 4B. Huerta y jardín de la casa anterior. Tapias de Manuel Bradi (1791). 
diente a la dicha casa Prâl y hazen esquina por la dha calle de el Prado a la dha de S. Augn...”. El ayuntamiento delegó la tirada de cuerdas al alarife Blas Rodríguez, tío de don Ventura, ${ }^{75}$ que dio órdenes al maestro que había de ejecutar la obra, Jerónimo Álvaro. El duque de Uceda vivía aún allí a principios de 1768, cuando tuvo lugar un incendio en la casa el 19 de enero. ${ }^{76}$

La otra casa fue edificada de nueva planta por encargo del XII duque y de su esposa, duquesa de Malpica, al arquitecto Francisco Sánchez [fig. 13]. ${ }^{77}$ Estaba situada en la calle de Alcalá con vuelta a la del Turco, manzana 273, sitio 1, en un pequeño solar de 43 pies a la primera calle y 85 pies a la segunda, que la duquesa debió de adquirir con una edificación que estaba derribando cuando el 28 de abril de 1783 solicitó la licencia. El edificio proyectado tenía portada a la calle del Turco con gran balcón encima adornado con cornisa sobresaliente sostenida por dos modillones, huecos rodeados de moldura plana y cocheras a la calle de Alcalá. Ventura Rodríguez exigió en su informe que la alineara con la casa que pertenecía a la duquesa en el sitio 11 de la misma manzana, en la calle del Turco.

En 1784, cuando se estaba construyendo la casa, se solicitó nueva licencia para elevar un piso más con diseño idéntico al de la planta principal [fig. 14]. ${ }^{78}$ El proyecto de Francisco Sánchez responde al mismo estilo clasicista de las casas madrileñas de los Medinaceli. En 1791, doña Petronila, ya duquesa viuda de Medinaceli, además de marquesa de Mancera y de Malpica, encargó a Manuel Bradi que reedificara la tapia del jardín y la de su huerta, que se hallaba en la manzana inmediata 272, calle de Alcalá con vuelta a la del Turco y a la de la Greda. ${ }^{79}$ Ocupaba el sitio 10 de la manzana, con frente de 372 y $1 / 2$ pies a la calle del Turco, por lo que la entrada a la huerta quedaría frente a la portada del palacete. Francisco Sánchez, actuando en esta ocasión como teniente de maestro mayor, ensanchó la calle tomando tres pies de la posesión de la duquesa.

Ilustramos sobre el plano de Antonio Espinosa de los Monteros de 1769 la situación de las casas a que nos referimos en esta publicación [fig. 15].

\section{BIBLIOGRAFÍA}

Agulló y Cobo, Mercedes (1983): “El maestro mayor de obras de Madrid don Ventura Rodríguez”. En: El Arqvitecto D. Ventura Rodrígvez (1717-1785). Madrid: Ayuntamiento, pp. 185-246.

Arquitectura y desarrollo urbano: Comunidad de Madrid (1998), Tomo V y (2004), Tomo IX. Madrid: Dirección General de Arquitectura y Vivienda, Fundación Caja Madrid y Fundación COAM.

Blanco Mozo, Juan Luis (1995-1996): "La cultura de Ventura Rodríguez y la biblioteca de su sobrino Manuel Martín Rodríguez". En: Anuario del Departamento de Historia y Teoría del Arte (UAM), Tomos 7-8, pp. 181-221.

Calatrava Escobar, Juan (1993): "Intervenciones diversas en proyectos de cuarteles". En: Rodríguez Ruiz, Delfín (coord.): Francisco Sabatini. 1721-1797. La Arquitectura como metáfora del Poder. Madrid: Electa / Comunidad de Madrid, pp. 521-525.

Cruz Yábar, María Teresa (2003): El escultor Manuel Álvarez (1721-1797). Tesis doctoral. Madrid: Universidad Complutense de Madrid. En: <https://eprints.ucm.es/id/eprint /12823/1/T27295.pdf>.

Cruz Yábar, María Teresa (2017): "Los retablos de Ventura Rodríguez". En: Rodríguez Ruiz, Delfín (coord.), Ventura Rodríguez. Arquitecto de la Ilustración. Madrid: Real Academia de Bellas Artes de San Fernando, pp. 169-205.

Cruz Yábar, María Teresa (2021): "Manuel Bradi”. En: Artífices de Madrid. Guía de arquitectos, ingenieros, paisajistas, alarifes y maestros de obras. Madrid: Instituto de Estudios Madrileños. En: https://institutoestudiosmadrileños.es/ artifices-de-madrid.

Gili Ruiz, Rafael (2017): Higiene y alcantarillado en el Madrid del Antiguo Régimen. Tesis doctoral. Universidad Autónoma de Madrid. En: http://hdl.handle.net/ 10486/679973 [12/III/2021].

Lopezosa Aparicio, Concepción (1999): Origen y desarrollo de un eje periférico de la capital, Prado de agustinos recoletos, Prado de San Jerónimo y Prado de Atocha. Tesis doctoral. Universidad Complutense de Madrid.

\footnotetext{
75 Blanco Mozo, 1995-1996: 183.

76 Diario noticioso, curioso, erudito y comercial público y económico, 8-II-1768, p. 4.

${ }_{77}$ AVM, Secretaría, 1-49-97.

78 AVM, Secretaría, 1-49-125.

79 AVM, Secretaría, 1-51-103. En la Planimetría General figura a nombre de las memorias del marqués de Mancera y medía 34.850 pies superficiales.
} 
Lopezosa Aparicio, Concepción (2019): "Manuel López Corona". En: Artifices de Madrid. Guía de arquitectos, ingenieros, paisajistas, alarifes y maestros de obras. Madrid: Instituto de Estudios Madrileños. En: < https://institutoestudiosmadrileños.es/artifices-de-madrid $>$ [16/III/2021].

Marín Tovar, Cristóbal (2000): "Nuevos datos documentales sobre el Cuartel de Reales Guardias de Corps de Madrid". En: Anales de Historia del Arte, 10, pp. 207-214.

Martínez Medina, África (1993): "Francisco Sabatini y sus colaboradores: la transformación de una ciudad. En: Rodríguez Ruiz, Delfín (coord.): Francisco Sabatini. 1721-1797. La Arquitectura como metáfora del Poder. Madrid: Electa/Comunidad de Madrid, pp. 357-369.

Martínez Millán, José (2009): “La casa de la reina Isabel de Farnesio (1715-1766): características y evolución”. En: Martínez Millán, José, Marçal Lourenço, Maria Paula (coords.): Las relaciones discretas entre las Monarquías Hispana y Portuguesa: las casas de las Reinas (siglos XV-XIX). Madrid: Polifemo, I, pp. 579-723.

Mayans y Siscar, Gregorio, Epistolario, Tomo VIII, pp. 437-438, Biblioteca Valenciana Digital, <https://bivaldi.gva.es/ $\mathrm{va} /$ corpus/unidad.do?posicion=1\&idCorpus $=20000 \&$ idUnidad $=50540>[24 / \mathrm{IV} / 2021]$.

Moleón Gavilanes, Pedro (2019): “Tiburcio Pérez Cuervo (1786-1841), arquitecto y masón”. En: Anales del Instituto de Estudios Madrileños, LIX, pp. 221-253.

Moleón Gavilanes, Pedro / Ortega Vidal, Javier / Sancho, José Luis (2017): Ventura Rodríguez y Madrid en las colecciones municipales. Madrid: Centro Cultural Conde Duque.

Morales, Nicolás / Quiles García, Fernando (2010): Sevilla y corte: las artes y el lustro real (1729-1733). Madrid: Casa de Velázquez.

Muñoz de la Nava Chacón, José Miguel (2015): Espacios públicos de ocio en el Madrid de Felipe II y Felipe III. Tesis doctoral. Universidad Complutense de Madrid.

Planimetria General de Madrid (1988). Madrid: Editorial Tabapress.

Pérez Arribas, Juan Luis (1915): Documentos de interés relacionados con la casa ducal de Medinaceli. Tomados del libro "Series de los más importantes documentos tomados del Archivo y Biblioteca del Excmo. Sr. Duque de Medinaceli elegidos por su encargo y publicados a sus expensas por Antonio Paz y Meliá, $1{ }^{a}$ Serie Histórica (800-1814). Recopilados y ordenados por José Luis Pérez Arribas, Madrid.

Ponz, Antonio (1776): Viage de España, Tomo V. Madrid: Joaquín Ibarra.

Romero Medina, Raúl (2004): "El palacio de los duques de Medinaceli y el proyecto inédito de Vicente de Acero para El Puerto de Santa María". En: Revista de Historia de El Puerto, 33, pp. 54-79.

Saint-Simon, Louis de Rouvroy, duc de (1857): Memoires complets et autentiques sur le siècle de Louis XIV et la Regence, $t$. VII. París: Librairie de L. Hachette et Cie.

Sambricio, Carlos (1979): "Luigi Vanvitelli y Francisco Sabatini; sobre la influencia de la arquitectura italiana en España". En: Boletín del Seminario de Estudios de Arte y Arqueología, 45, pp. 427-438.

Sánchez González, Antonio (ed.) (2017): El Arte de la representación del espacio. Mapas y planos de la colección Medinaceli. Huelva, Universidad de Huelva.

Sancho, José Luis (1993): "Dirección de diversos edificios para la Real Casa". En: Rodríguez Ruiz, Delfín (coord.): Francisco Sabatini. 1721-1797. La Arquitectura como metáfora del Poder. Madrid: Electa/Comunidad de Madrid, pp. 260-262.

Sempere y Guarinos, Juan (1789): Descripción de los ornatos públicos con que la Corte de Madrid ha solemnizado la feliz exaltación al trono de los Reyes nuestros señores Don Carlos IIII y Doña Luisa de Borbón, y la jura del serenísimo Señor Don Fernando, Príncipe de Asturias. Madrid: Imprenta Real.

Tovar Martín, Virginia (1991-1992): "La Casa de Oficios (casa de caballeros, de oficiales y criados) en el Real Sitio de El Pardo". En: Anales de Historia del Arte, 3, pp. 185-205.

Vizcaíno Villanueva, María A. (1991-1992): "La iglesia de San Salvador en el Antiguo Madrid”. En: Anales de Historia del Arte, 3, pp. 143-158.

Fecha de recepción: 31-V-2021

Fecha de aceptación: 26-VII-2021 